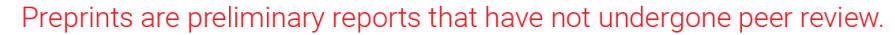 They should not be considered conclusive, used to inform clinical practice, or referenced by the media as validated information. \\ Prediction of Fatigue Crack Growth Rate in Aircraft Aluminum Alloys Using Optimized Neural Networks
}

\section{Hassan Bin Younis}

Institute of Control Systems, Rawalpindi

Khurram Kamal

National University of Sciences and Technology

Muhammad Fahad Sheikh ( $\square$ muhammad.fahad@skt.umt.edu.pk)

University of Management and Technology https://orcid.org/0000-0002-0124-4838

\section{Amir Hamza}

National University of Sciences and Technology

\section{Original Article}

Keywords: Artificial Neural Network, Genetic Algorithm, Hill Climbing, Simulated Annealing, Stress Intensity Factor

Posted Date: November 25th, 2020

DOI: https://doi.org/10.21203/rs.3.rs-113296/v1

License: (c) (1) This work is licensed under a Creative Commons Attribution 4.0 International License. Read Full License

Version of Record: A version of this preprint was published at Theoretical and Applied Fracture Mechanics on November 1st, 2021. See the published version at https://doi.org/10.1016/j.tafmec.2021.103196. 


\title{
Prediction of Fatigue Crack Growth Rate in Aircraft Aluminum Alloys Using Optimized Neural Networks
}

\author{
Hassan Bin Younis ${ }^{1}$, Khurram Kamal' ${ }^{2}$ Muhammad Fahad Sheikh³ ${ }^{3}$ Amir Hamza ${ }^{4}$ \\ ${ }^{1}$ Institute of Industrial Control Systems, Rawalpindi, Pakistan \\ ${ }^{2,4}$ National University of Sciences and Technology, Pakistan \\ ${ }^{3}$ University of Management and Technology, Sialkot, Pakistan
}

\begin{abstract}
In aerospace industry, Fatigue Crack Propagation pose a serious threat in designing mechanical assembly of the aircraft structures. In these structures crack growth is a problem to be handled seriously, as human life risk is concerned in addition to economic loss. Fatigue Crack Growth (FCG) Rate is the rate at which crack grows with number of cycles subjected to constant amplitude loading. Upon analyzing the curve it becomes obvious that the correlation between Stress Intensity Factor (SIF) range " $\Delta K$ " with FCG rate " $d a / d N$ " is deviating linear relationship considering region II of the curve that is also called Paris Region. Empirical formulation methods cannot deal with linearity factor satisfactorily. In contrast to the prior methods, machine learning algorithms are capable to deal with the non-linearity issue in a much better way owing to their admirable learning ability and flexible nature. In this research work Genetic Algorithm, Hill Climbing Algorithm and Simulated Annealing Algorithm based Optimized Neural Networks were utilized for prediction of FCG rate. Proposed technique was validated by testing on different aerospace aluminum alloys including 2324-T39, 7055-T7511 and 6013-T651. The least predicted MSE was $1.0559 \times 10^{-9}$ achieved for aluminum alloy 6013-T651 by Simulated Annealing based optimized Neural Network. Moreover, the results demonstrate an exceptional conformity to the data conceived during experimentation process.
\end{abstract}

Keywords: Artificial Neural Network; Genetic Algorithm; Hill Climbing; Simulated Annealing; Stress Intensity Factor

\section{Introduction}

In material sciences, damage tolerance is gaining immense significance. The structural failures especially in aircrafts and high speed trains are mostly due to Fatigue Crack Growth. In engineering, fatigue is a procedure in which material fails during the application of considerable cyclic loading. Under this type of failure, engineering components distort as a result of internal force that is further down the standard strength of the material. These types of accidents pose great dares in locomotive and airplane industries as it involves the human lives most importantly. Versailles Train Crash in 1842, De Havilland Comet Plane Crashes in 1954 and Eschede Train Disaster in 1998 are some of the examples in which structure failure occurred due to material fatigue, causing many causalities besides enormous financial loss. These types of accidents urged the professionals in this sector to predict Fatigue Crack Growth Rate (FCG). The accurate prediction of FCG became the next challenge for the experts as there was no room for error considering the life risk of passengers.

Due to this reason, Fatigue Crack Growth Rate (FCG) turn out to be crucial and essential that need to be considered on a regular basis. The performance of crack development due to fatigue is described by growth rate $d a / d N$ and Stress Intensity Factor (SIF) range $\Delta K$. This specific graph contains $\Delta K$ and $d a / d N$ on $\mathrm{x}$-axis and y-axis respectively in which $a$ represents the size of crack while $N$ represents total number of cycles leading to failure. This graph is distributed into three specific sections. Among these regions, region II is of maximum importance in which Paris Law holds and is called Paris region. In the above mentioned section, a claim was made by researchers that the curve depicts a linear correlation amongst the concerned quantities. Afterwards, with the help of healthy experimentation taking various materials under consideration, it is witnessed that relationship between FCG rate and SIF deviates from linear behavior even in Paris region

To fix the non-linear relationship between the above mentioned variables, many models have been proposed since the discovery of the problem. The following proposed prototypes are centered at the principle of Linear Elastic Fracture Mechanics. Paris et al. [1] presented an analytical formulation for comparison of an extensive collection of data for certification of crack propagation laws. The authors claimed that in preceding approaches a wider span of data in order to authenticate these laws was not used but the disadvantage in this technique is that non-linearites are not taken into consideration for not even the Paris region (region II). Moreover, this methodology was proposed 
without considering various other parameters. Other authors continued their research to devise the models that would cater for the non-linearity and other factors. Forman et al. [2] proposed an improved method in order to analyze crack growth rate subjected to cyclic loading. This theory takes into account other ignored parameters in previous methods that include load ratio, $\mathrm{R}$ and fracture toughness, $K_{c}$. The main weakness in Forman's technique is that it does not cater for fracture toughness at threshold, $\Delta K_{t h}$. Moreover, it was unable to explain the deviation from linear behavior in Paris region. In Priddle's model [3], essential factors are taken into account that are capable to suit the deviation from rectilinear behavior in Paris region of the characteristic curve. On the other hand, the limitation in the explained methodology is that it is unable to accommodate R-ratio effect. Elber et al. [4], on the basis of the mechanism upon which fatigue crack grows introduced the concept of crack closure effect. He explained that under the time span of cyclic loading (tension), crack induced as a result of fatigue closes automatically provided that the load applied is half the maximum load. This model has an advantage that it cannot only be applied to three regions of crack propagation but it includes stress ratio effects ignored earlier. The major drawback in this model is that theoretically this model only covers limited range of stress ratio, R. Furthermore, many researchers carried on their research to rectify the issue of non-linearity. Kujawski et al. [5], Donald et al. [6] and Sandananda et al. [7] are amongst them. They proposed a new concept of mechanical driving force for both long and short crack growth rates instead of crack closure concept. According to the authors $\Delta \mathrm{K}$ and $\mathrm{K}_{\max }$ are the two parameters that help in calculating fatigue crack propagation. Making this research as a base Dinda et al. [8] proposed an approach to predict stress-ratio effects on fatigue crack growth rate. This method is named as $K^{*}$ method where $K^{*}$ is the fatigue crack driving force. Mathematically, $\mathrm{K}^{*}$ and fatigue crack growth rate can be expressed as:

$$
\begin{aligned}
& K^{*}=\left(K_{\max }\right)^{\alpha}\left(\Delta K^{+}\right)^{1-\alpha} \\
& d a / d N=f\left(K^{*}\right)
\end{aligned}
$$

where $\alpha$ is correspondence constraint, and $\Delta K^{+}$is the positive portion of useful $\Delta K$. In correlation with the previous study, this approach is equally effective or better by taking into account $K_{\max }$ and $K^{+}$as it excellently deals with the non-linearity in region II. On the other hand, this method cannot calculate the correlation parameter, $\alpha$ and $R$-ratio effects for different materials accurately in all the three regions of $d a / d N-\Delta K$ curve. Since the discovery of the problem, many researchers have been struggling to provide an analytical formula in order to solve the non-linearities in FCG rate. In such efforts, many parameters like $\Delta K_{t h}, R, K_{c}$ and $\Delta K_{\text {eff }}$ are involved. In reality, mathematical formulas are obstinate to provide a solution for ordinary as well as multi-variable problems. It is quite challenging to discover an exclusive and general methodical relation for such circumstances.

Analytical methods could not address the case well. To overcome the limitations, researchers started thinking other ways and more multidisciplinary methods were brought together. Amongst many, numerical approach and machine learning based methods are proved to be most operative. A hybrid approach combining numerical methods and machine learning algorithms was also presented in different ways. Bui [9] developed an efficient and improved knowledge based neural network (KBNN) accompanied with Finite Element Analysis (FEA) to predict to accurately predict spring back angles in bending of metal sheet. Bhattacharya et al. [10] used extended finite element method (XFEM) to examine crack growth in dual coated materials. Hu et al. [11] proposed a new technique of singular finite element which includes fracture process zone (FPZ) lying in front of crack tip by utilizing cohesive zone model (CZM). The aim was to learn fatigue crack growth under variable amplitude cyclic loading. Presently, machine learning based methods showed the better results and are being considered to be most interesting and capable while catering the case due to the admirable tolerance and estimation to non-linear and multi-variable complications. Amongst those algorithms, support vector machine (SVM), genetic algorithms, artificial neural network (ANN), fuzzy logic, neural-fuzzy system and particle swarm optimization (PSO) are prominent. Mohanty et al. [12] used artificial neural network (ANN) to predict fatigue crack propagation life of aluminum alloys. Rodríguez [13] and Rafiq [14] also used ANN for different engineering applications. Venkatesh et al. [15] used back propagation neural network for accurate life prediction of materials subjected to creep-fatigue behavior at raised temperature. He demonstrated his idea using Ni-based alloy. Artymiak et al. [16], Kang et al. [17], Haque et al. [18] and Cheng et al. [19] used machine learning algorithms for different fatigue problems. Zio et al. [20] utilized a Bayesian elaboration of support vector machine (SVM) called relevance vector mechine (RVM) in oreder to give a prediction of the remaining useful life of a structure under a safety-critical standard. Mohanty et al. [21] proposed a genetic algorithm in order to predict fatigue life of a material. He demonstrated it using 2024-T3 aluminum alloy. Zhang et al. [22] used an ANN based algorithm, RBF-NN for proposal of a fatigue life prediction model. Wang et al. [23] compared three MLA based algorithm in order to predict FCG rate. These include GABP-NN, RBF-NN and ELM. ELM has come out to be most accurate among others. 
Firstly, a 2-input and a single output data is extracted from the literature. For this proposed technique $\Delta \mathrm{K}$ and $R$ are taken as input and $d a / d N$ as output. After that the experimental data is prepared and processed in order to make it able to be used in the MLA's. The data is segregated amongst training and testing arrays. The neural networks are trained for maximum iterations using training set of data until a preset mean square error (MSE) is achieved or maximum iterations are performed. After achieving required value of MSE or running maximum iterations, the undergoing network is trained and the weights are freezed. This trained neural networks are tested to see which of the algorithm best fits the linearity issue in Paris region during the process of crack propagation.

\section{Background theory}

\subsection{Introduction to Fracture Mechanics:}

The engineering structures are exposed to mechanical discontinuities. One of the prone discontinuities includes that are produced in fuselages in aircraft structures. Fracture Mechanics describes as an arrangement of theories depicting the conduct of solids or structures with geometrical irregularities at the size of the structure. Usually, the application of force is in any of the following manners as shown in Fig. 1.

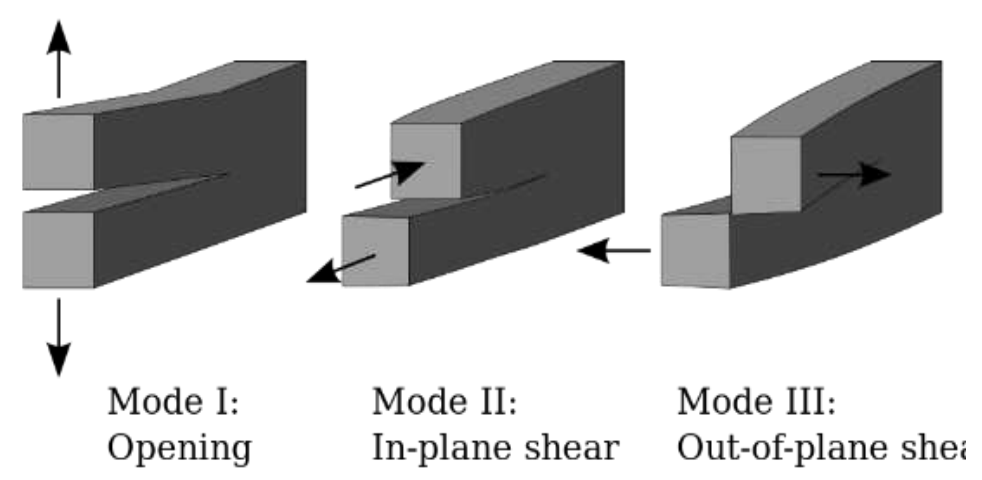

Fig. 1. Modes of Failure during Engagement of Crack Propagation

The fatigue rate curve is a graph between $\mathrm{da} / \mathrm{dN}$ and $\Delta K$ as shown in Fig. 2. The graph has three regions i.e. Region I, II and III. In region I, the early crack rate development is represented. In this region, crack propagation rate is less than or equal to $10^{-6} \mathrm{~mm} /$ cycle. Region II is also named as intermediary region. In this zone, the FCG rate is between $10^{6}-10^{3} \mathrm{~mm} / \mathrm{cycle}$. FCG rate is stable throughout this region. Finally, region III starts. In this region, Fig. 2 depicts clearly that the curve again starts inclining. It is generally in the order of $10^{3} \mathrm{~mm} /$ cycle or even more. This is remembered as extraordinary fatigue crack growth rates that are the results of frequent and unbalanced growth preceding to absolute failure of the specimen. 


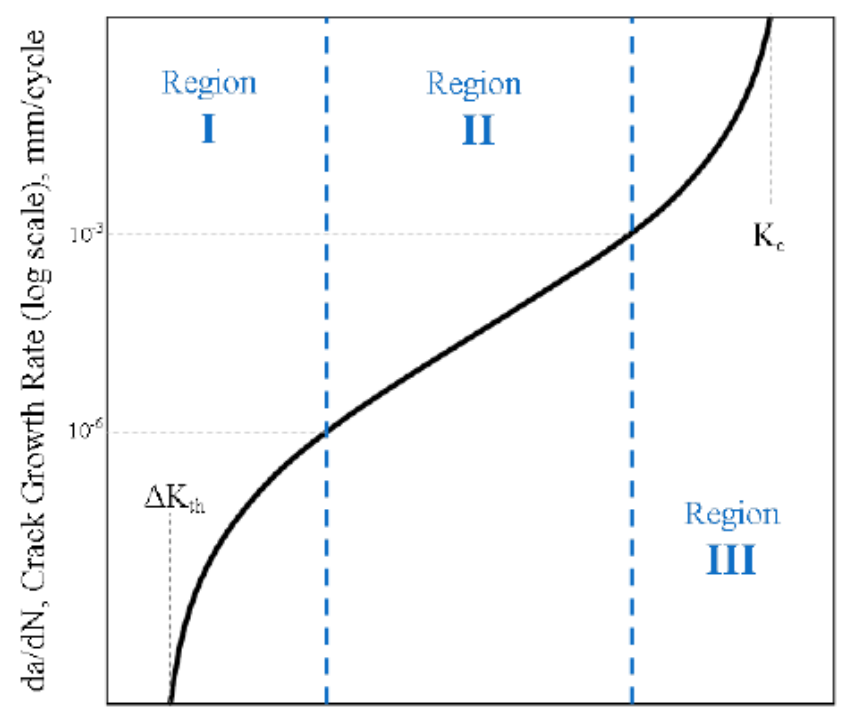

$\Delta K$, Stress Intensity Range (log scale)

Fig. 2. Generalized Fatigue Crack Growth Rate Curve

\subsection{Artificial Neural Networks:}

There are a number of problems that cannot be dealt with a computer algorithm. Human beings have learning capability which computer processor lacks. The impressive quality of a brain of living things is that they learn on their own accompanied with prior knowledge and information gathered from environment. Computers have a program on which it works depending upon the application. What do we need in computers to replicate brain like capability to decide on their own? The idea is developed from a biological process of transferring information and decision making i.e. neurons. So, an artificial neural network is made to serve the purpose. A structure of an artificial neural network is shown in Fig. 3.

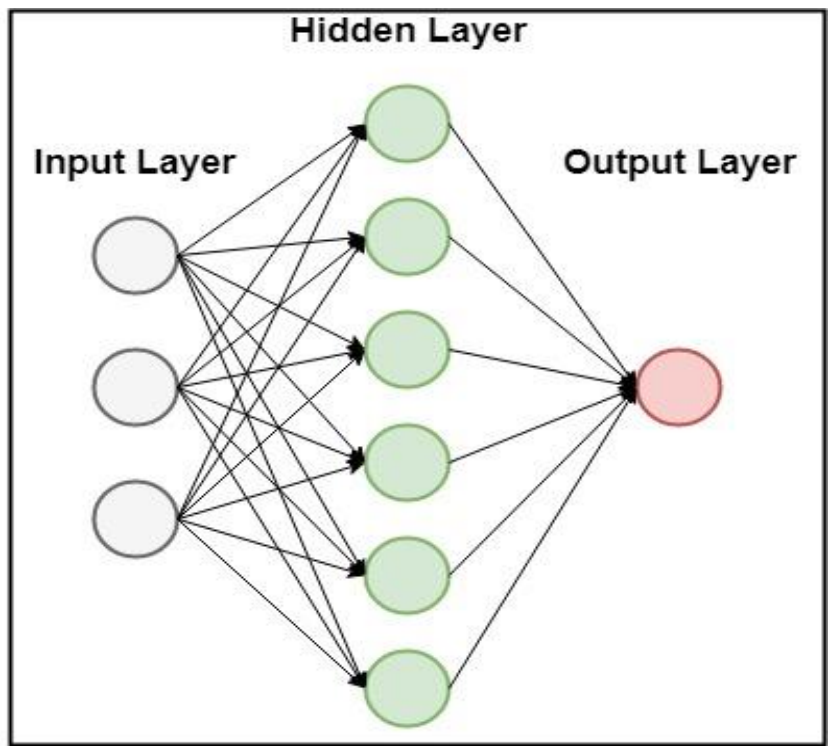

Fig. 3. A Structure of a Feed Forward Neural Network

To have a better understanding of an Artificial Neural Network it is necessary to have an insight on how conventional computer works. A computer has a Central Processing Unit that addresses a memory location where a data or instruction is stored depending upon the program. The processing unit perform an operation and results are stored in a specific memory location according to the requirement. In this computational system, instructions are 
sequential or logical and a state of a given variable can be traced from operation to operation. In contrast to serial computers, ANN's working is not sequential or deterministic. They do not execute program directions; they react to the information source provided as they come across. Moreover, updated information is stored in activation "state" of the system instead of storing it in the separate memory location like serial computers. ANN is briefly explained as follows.

An Artificial Neural Network (ANN) is formed by inter linkage of connecting elements. The data is treated by their active reaction to outer inputs. The motivation comes from biological neural networks. ANN's may include a hardware computing device or an algorithm that are modeled after observing a neuronal structure of mammals but on a much smaller scale obviously. Some larger networks contain hundreds or thousands of connections and processing units but a biological neural network contains billions of neurons. An Artificial Neural Network is structured in the form of layers. The layers consist of nodes interconnected with each other which are powered by an Activation Function. The pattern of the systems is presented to the network by an input layer which communicates to one or more hidden layers for processing. Hidden layers possess weighted functions which is the actual driving force of processing. After processing, hidden layers involved in the process communicate to the output layers where information is transferred as output of the network. An ANN has the learning rule which continuously modifies the weights of the connections according to the input presented. So, the basic components of a network come out to be as follows:

- Neurons

- Connection and Weights

- Propagation Function

- Learning Rule

\subsection{Artificial Neural Network Optimization:}

Generally, when we talk about optimization of Artificial Neural Networks the main concern is objective function which is the mean square error function. The aim is to optimize the values of weighted connections in order to minimize mean square error i.e. objective function. The following is a brief introduction of the optimization techniques used in this paper

\subsection{Hill Climbing based Optimized Neural Network:}

Hill climbing is a type of an optimization techniques in artificial intelligence the is very useful in solving the problems with complex hierarchy. It always keeps itself busy in monitoring current state and future state and tends to improve the current state with the help of an evaluation function while performing iterations. Basically, it is seen as a loop that continuously keep on moving towards the increasing value and terminates when highest peak is met. i.e. no neighbor is around with the higher value. The loop is run in a way that best known solution at the present stage $\mathrm{m}_{\text {current }}$ is reproduced in the form of an offspring $\mathrm{m}_{\text {neighbor }}$. If the reproduced offspring $\mathrm{m}_{\text {neighbor }}$ is better in value than $\mathrm{m}_{\text {current }}$, it is updated and becomes $\mathrm{m}_{\text {current }}$, otherwise it is neglected and cycle continues to search for a new solution or cessation condition. It is a local search algorithm that only looks for its immediate neighbors. Following is the pseudo code for the presented algorithm.

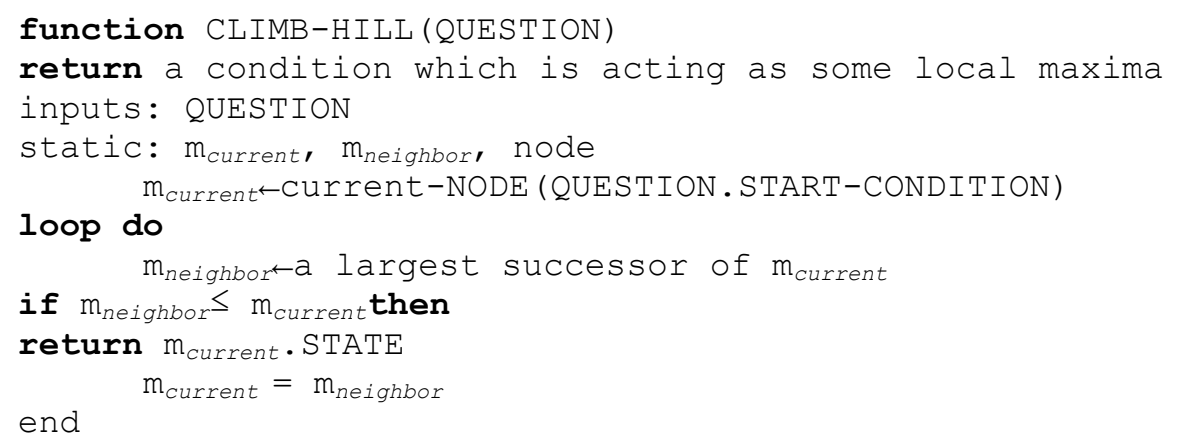


Following is the flowchart explaining the application of Hill Climbing based Optimized Neural Network for the proposed technique

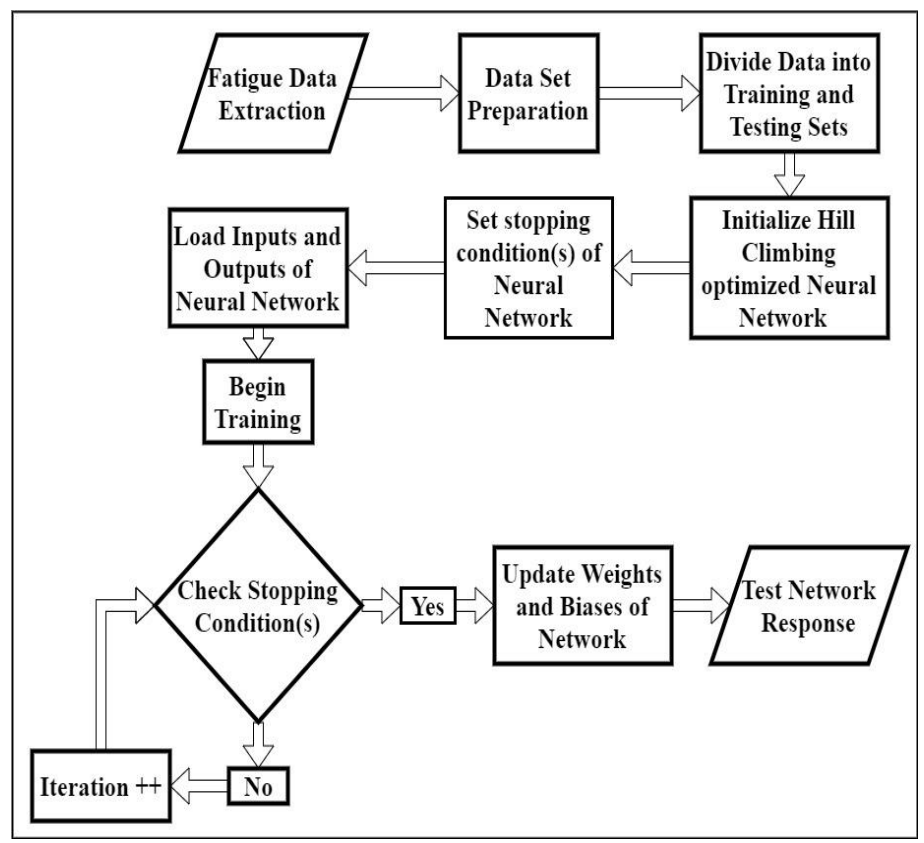

Fig. 4. A Flowchart of Proposed Technique using Hill Climbing Based Optimized Neural Network

\subsection{Simulated Annealing Based Optimized Neural Network:}

Simulated Annealing is a probabilistic search which look for a single suitable solution. It takes its concept form the process of annealing in the field of metallurgy. Annealing is a process where metals are heating above their melting points, hold and then cooled slowly to solidified form attaining minimum energy configuration in order to get a perfect crystalline molecular structure. The purpose is to find a global minimum when various algorithms stuck in local minima. The innermost loop of this algorithm runs same as of hill climbing but the difference between these two is that it searches for random move instead of best move. If that move is better than current, it is updated otherwise the algorithm searches for another one. Following is the flowchart of the simulated annealing process

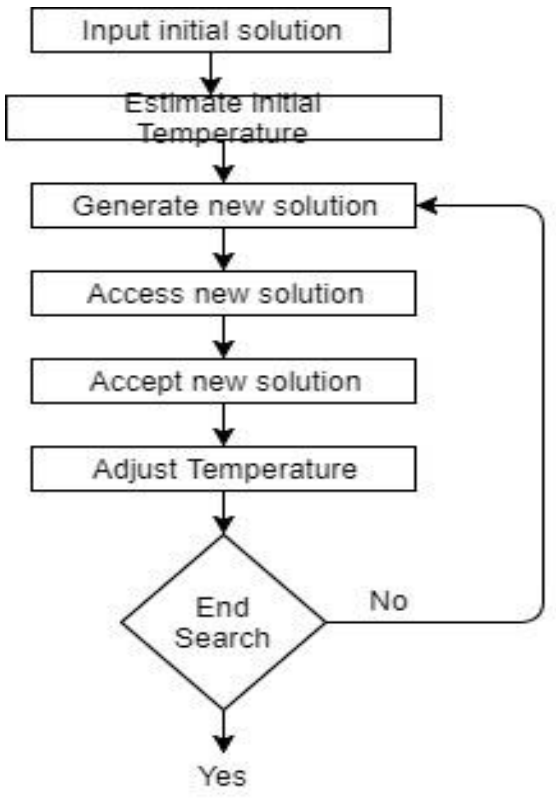

Fig. 5. A Flowchart of Generalized Simulated Annealing Based Optimized Neural Network 
Following is the pseudo code for Simulated Annealing based Optimized Neural Network:

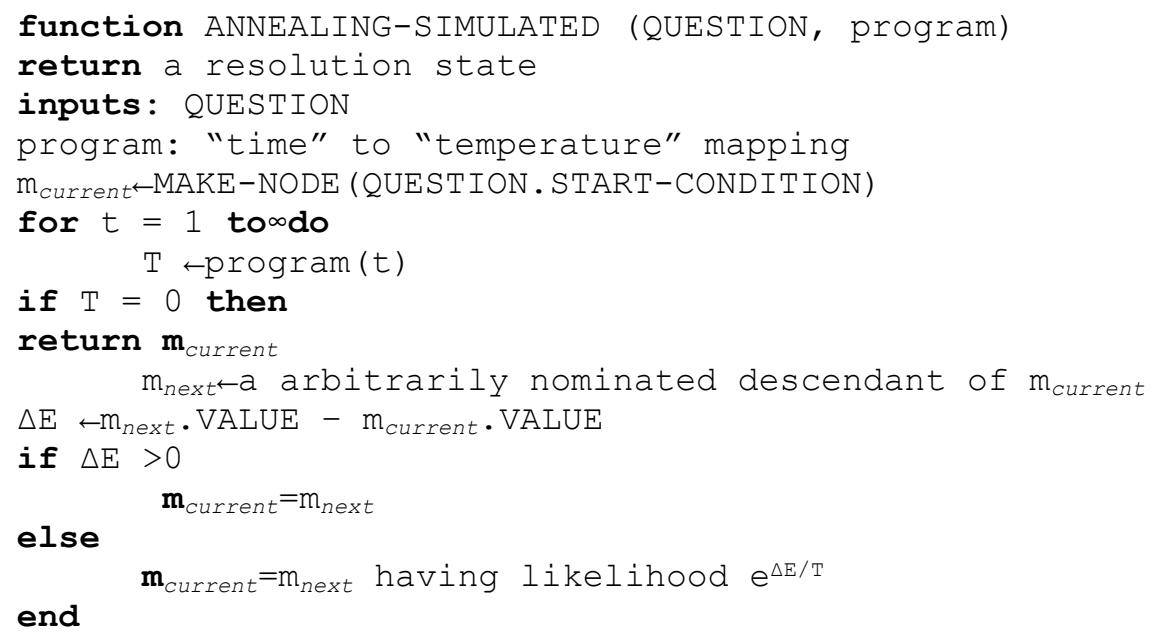

A flowchart shown in Fig. 6 explains the application of Simulated Annealing based Optimized Neural Network for the proposed technique

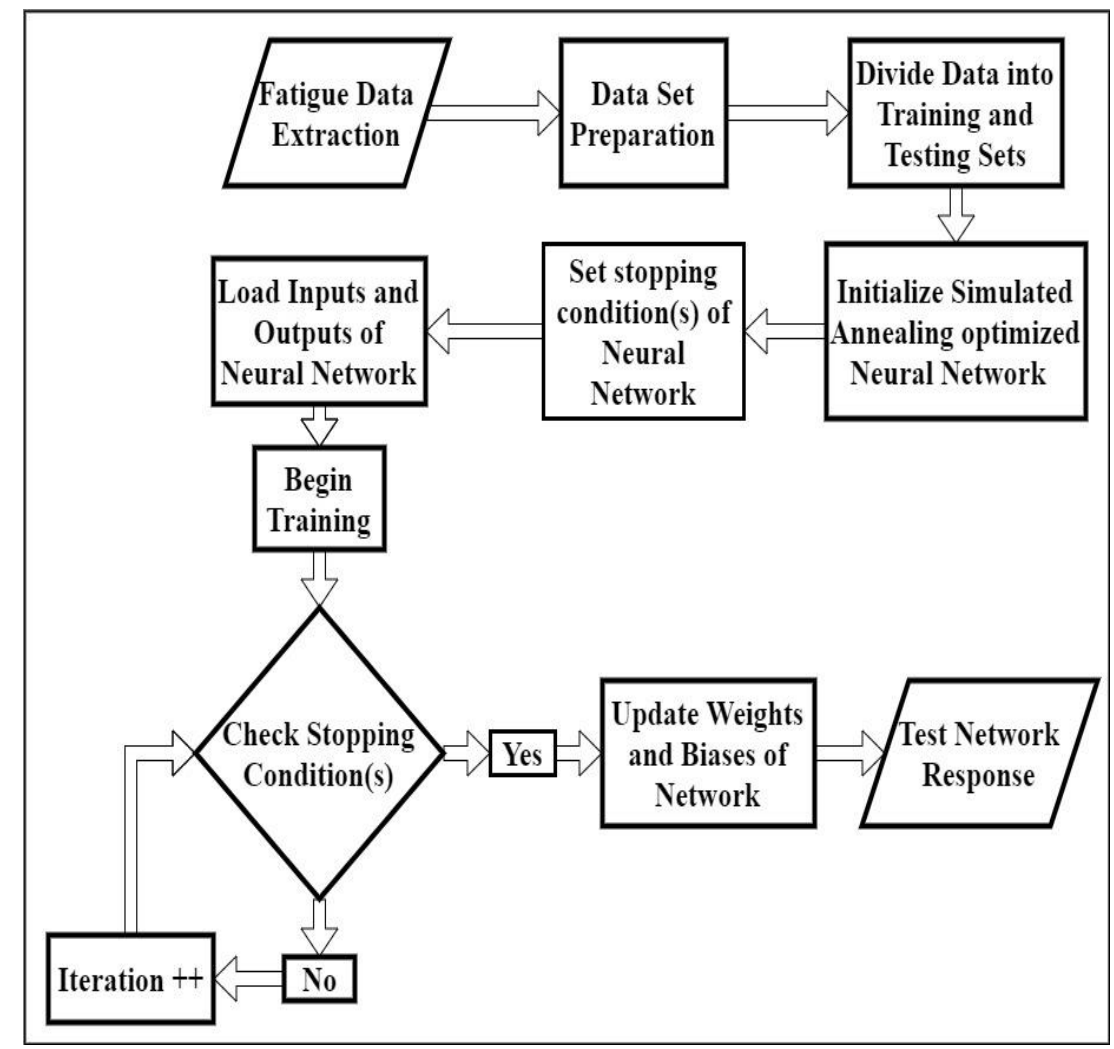

Fig. 6. A Flowchart of Proposed Technique using Simulated Annealing Based Optimized Neural Network

\subsection{Genetic Algorithm Based Optimized Neural Network:}

For hard, non-linear capacities Genetic Algorithm has been performing exceptionally good in acquiring worldwide arrangements. Fundamentally, a goal, for example, minimization of the sum of squared errors or total of absolute errors, is decided for optimizing the neural system. Having a benefit of selected goal point, each candidate acquires attention to the fundamental population of randomly selected initial points are used for analyzing the goal 
position. The mentioned characteristics are then used as a part of assigning chances for each of the emphases that are included in the population set. To achieve minimization, that is the case of sum of squared errors, the point having the lowest objective function is assigned the highest probability. When each point is assigned its respective probability, a new population of points is drawn from the present population as a replacement. The points are picked arbitrarily with the probability of acceptance, equal to a probability value that is allotted to it. Therefore, the points with minimum sum of squared errors are most favorites to be represented in the new population. The points consisting a new population are then arbitrarily made in pairs for crossover. Each point is represented as a string of $\mathrm{n}$ different weights. A position along a string is arbitrarily selected for sole set of points and previous constraints are swapped between these points. Each crossover gives a new point having constraints from both parent points. As a result, each weight has much less chance of being replaced with a value arbitrarily selected from the parameter space. This is called mutation. Mutation augments the Genetic Algorithm by occasionally inserting a random point for a better search of whole parameter space. In this way the Genetic Algorithm is permitted to escape from local optima provided the new generated point proves to be a better solution than those that have been previously found better. This provides a more robust solution. Thus, resulting set of points becomes the new population, and the cycle repeats until a best solution converges.

As, this method seeks in numerous ways at times, the chance to discover a globally ideal increments. The arithmetic's comparability to regular choice inspires its name. As the Genetic Algorithm moves forward through ages, the superlative parameters to optimize the target capacity will repeat in finding who and what is to come, while the parameters that are ineffective comparatively vanish in survival of the best solution. Following is a pseudo code, explaining the algorithm

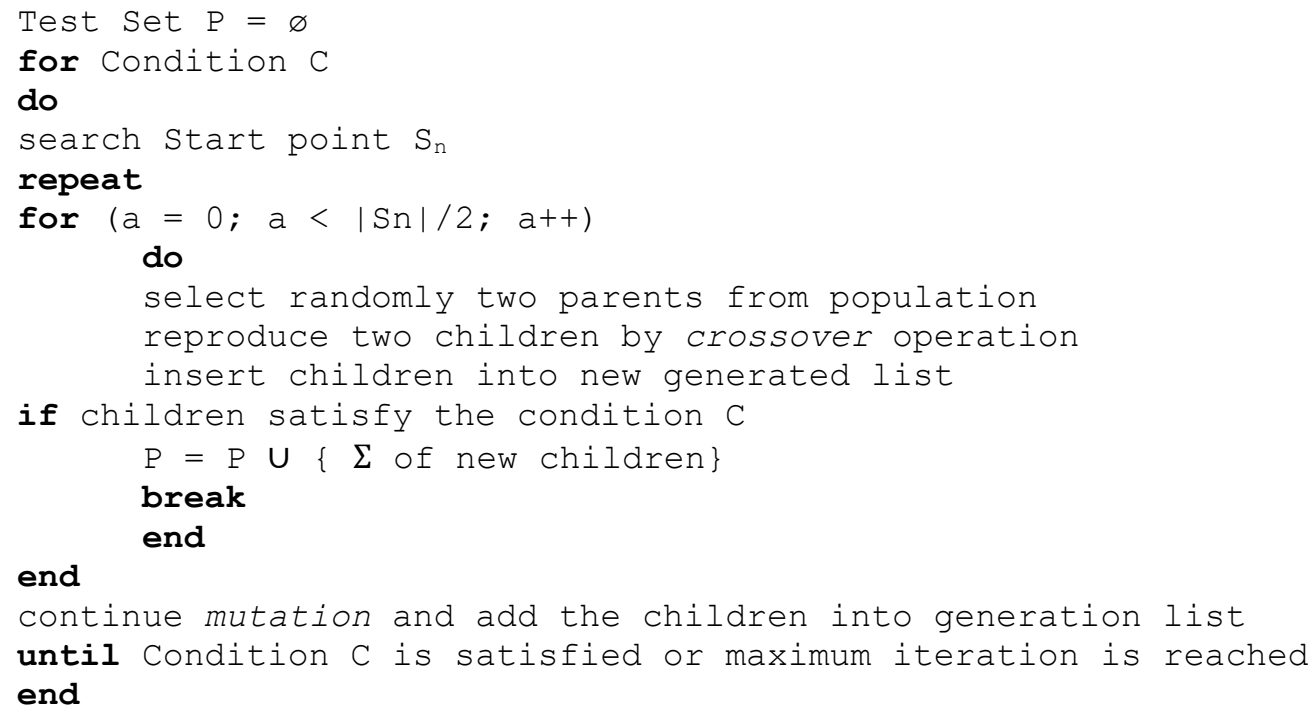

Following flowchart as shown in Fig. 7 explains the application of Genetic Algorithm based Optimized Neural Network used in the proposed technique. 


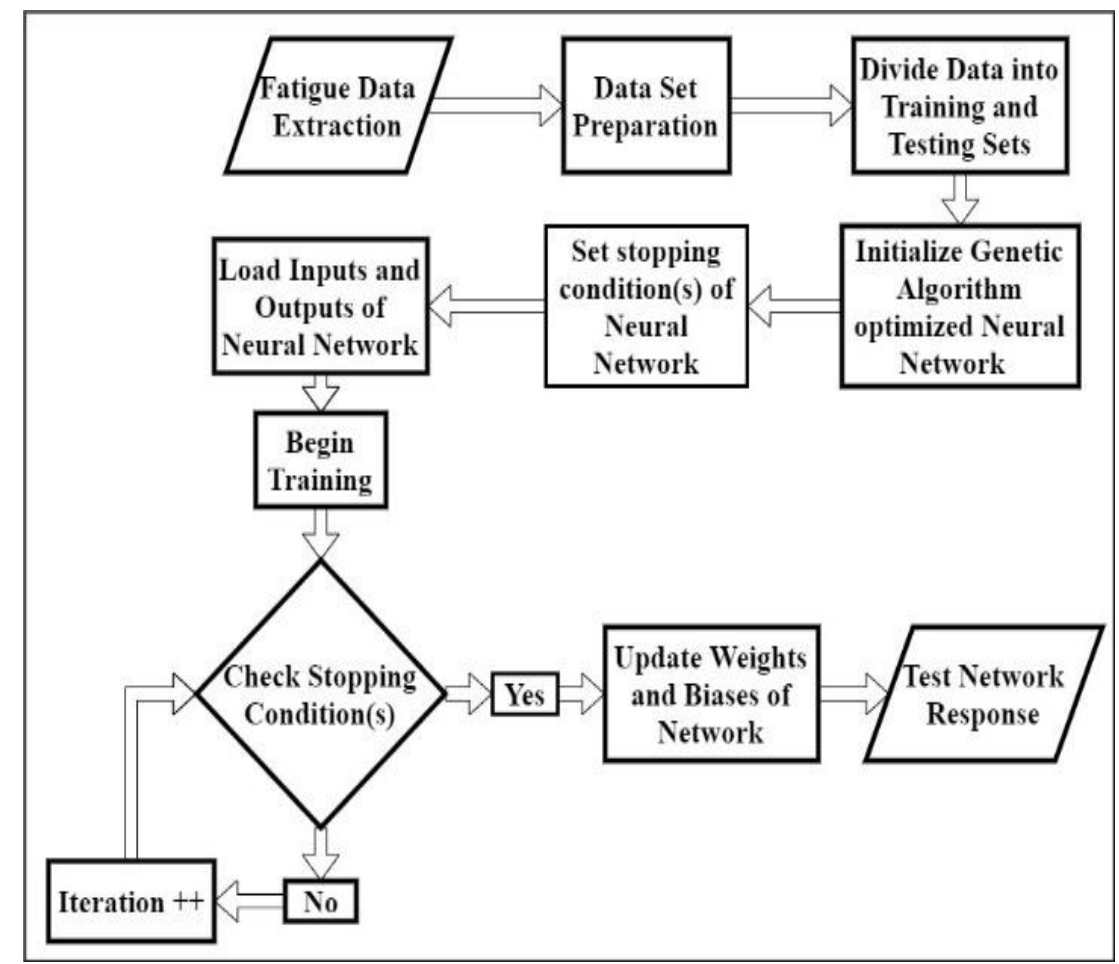

Fig. 7. A Flowchart of Proposed Technique using Genetic Algorithm Based Optimized Neural Network

\section{Experimentation and Results}

\subsection{Data Acquisition:}

The experimental information is carried out for some aluminum alloys with load ratios in the range of 0.1-0.7, acquired through experimentation on different alloys conducted in Fracture Technology Associates Laboratory. This data has previously been used by Wang et al. [23], Paris et al. [24] and Donald et al. [25] in their research work. Experimentation was held out on a hydraulic testing apparatus connected to a devoted PC to acquire the data efficiently and control other factors. Strain gauge based sensors are used for measurement purpose of the displacement. The data extracted through experimentation is plotted for the understudy materials inside a given span of load ratios. A summary of the testing environment undertaken during experimentation is as followed

Table 1: Summary of Testing Environment of during Experimentation [25]

\begin{tabular}{|c|c|}
\hline $\begin{array}{c}\text { Specimen Physical } \\
\text { Characteristics }\end{array}$ & $\mathbf{M}(\mathbf{T})$ \\
\hline Thickness $(\mathrm{B})$ & $\begin{array}{c}2.3 \mathrm{~mm}-3.3 \mathrm{~mm} \text { (Dissimilar for each } \\
\text { sample) }\end{array}$ \\
\hline Width $(\mathrm{W})$ & $1.016 \times 10^{-5} \mathrm{~m}$ \\
\hline Notch Length $\left(2 \mathrm{a}_{0}\right)$ & $1.02 \times 10^{-4} \mathrm{~m}$ \\
\hline Orientation & $\mathrm{L}-\mathrm{T}$ \\
\hline Test Frequency & $15 \mathrm{~Hz}$ \\
\hline Environment & $\begin{array}{c}\text { Laboratory Ambience, } 23^{\circ} \mathrm{C}, \mathrm{R} . \mathrm{H}=51- \\
55 \%\end{array}$ \\
\hline$d a / d N$ & $1 \times 10^{-12}$ to $1 \times 10^{-4} \mathrm{~m} / \mathrm{cycle}$ \\
\hline
\end{tabular}


The useful properties for 2324-T39 Aluminum Alloy are mentioned in the Table 2.

Table 2. Useful properties for 2324-T39 Aluminum Alloy [25]

\begin{tabular}{|c|c|}
\hline \multicolumn{2}{|c|}{ Physical Properties (Metric) } \\
\hline Density & $2.77 \mathrm{~g} / \mathrm{cc}$ \\
\hline \multicolumn{2}{|c|}{ Mechanical Properties (Metric) } \\
\hline UTS & $\geq 470-475 \mathrm{MPa}$ \\
\hline $\begin{array}{c}\text { Tensile Strength at Yield } \\
\text { Point }\end{array}$ & $\geq 365-370 \mathrm{MPa}$ \\
\hline Extension at Breaking Point & $\geq 7.9 \%$ \\
\hline Young's Modulus (E) & $72.4 \times 10^{9} \mathrm{~Pa}$ \\
\hline$\mu$ & 0.3 \\
\hline \multicolumn{2}{|c|}{ Electrical Properties (Metric) } \\
\hline Electrical Resistivity & $4.5 \times 10^{-8} \Omega-\mathrm{m}$ \\
\hline \multicolumn{2}{|c|}{ Thermal Properties (Metric) } \\
\hline $\begin{array}{l}\text { Co-efficient of Thermal } \\
\text { Expansion (Linear) }\end{array}$ & $\begin{array}{c}2.32 \times 10^{-7} \mathrm{~m} / \mathrm{m}-{ }^{\circ} \mathrm{C} @ 20.0^{\circ} \mathrm{C} \\
2.47 \times 10^{-7} \mathrm{~m} / \mathrm{m}-{ }^{\circ} \mathrm{C} @ \\
20.0-300^{\circ} \mathrm{C}\end{array}$ \\
\hline Specific Heat Capacity & $8.749 \times 10^{-1} \mathrm{~J} / \mathrm{g}^{\circ} \mathrm{C}$ \\
\hline Conductivity (Thermal) & $151 \mathrm{~W} / \mathrm{m}-\mathrm{K}$ \\
\hline
\end{tabular}

When 2324-T39 Al alloy is considered, the extracted data acquired from experimentation while taking diverse load ratios is plotted using MATLAB software and that is shown in Fig. 8.

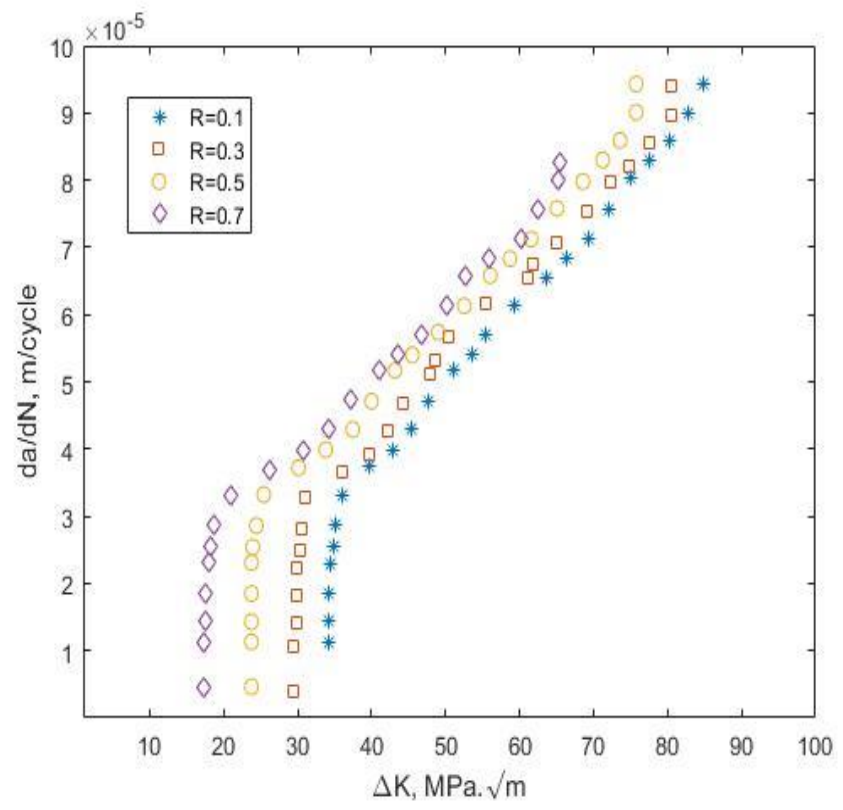

Fig. 8. Extracted data of Fatigue Crack Growth rate of 2324-T39 Al alloy through experimentation

Likewise, in case of 7055-T7511 Al alloy, the extracted data acquired from experimentation while taking diverse load ratios is plotted using MATLAB software and that is shown in Fig. 9 


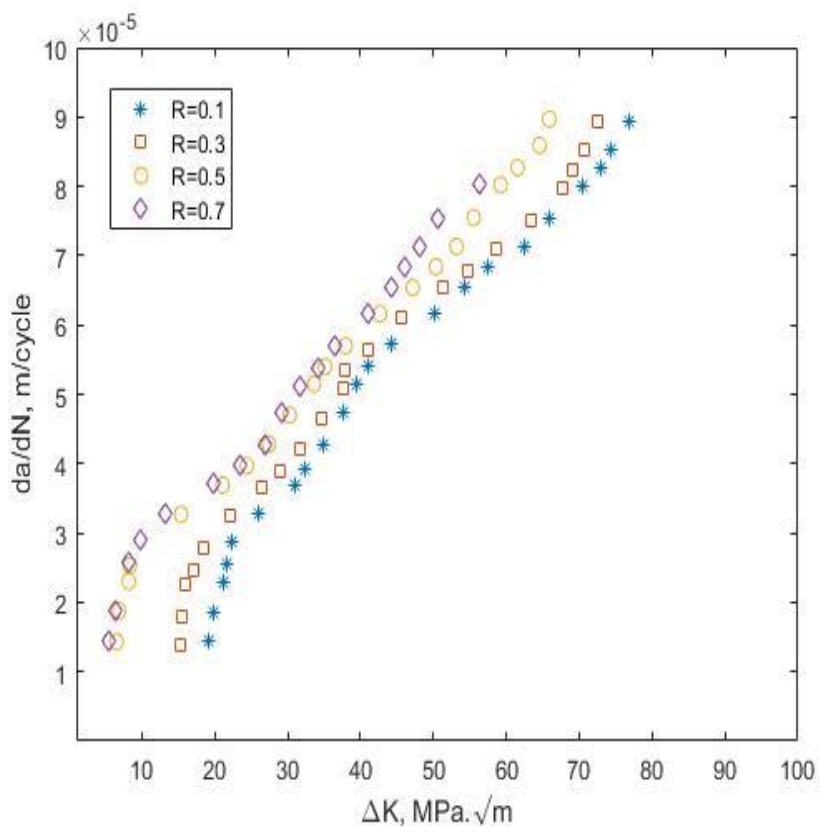

Fig. 9. Extracted data of Fatigue Crack Growth rate of 7055-T7511 Al alloy through experimentation

The useful properties of 6013-T651 Aluminum Alloy are mentioned in the Table 3

Table 3. Useful properties for 2324-T39 Aluminum Alloy [25]

\begin{tabular}{|c|c|}
\hline \multicolumn{2}{|c|}{ Physical Properties (Metric Units) } \\
\hline Density & $2.71 \mathrm{~g} / \mathrm{cc}$ \\
\hline \multicolumn{2}{|c|}{ Mechanical Properties (Metric Units) } \\
\hline Brinell's Test & 129 \\
\hline Knoop's Test & 164 \\
\hline Rockwell 'A' Test & 50 \\
\hline Rockwell 'B' Test & 79.99 \\
\hline Vicker's Test & 149.9 \\
\hline UTS & $\geq 3.79 \times 10^{8} \mathrm{~Pa}$ \\
\hline Tensile Strength at Yield Point & $\geq 3.58 \times 10^{8} \mathrm{~Pa}$ \\
\hline Extension at Breaking Point & $5.0 \%$ \\
\hline Young’s Modulus (E) & $6.69 \times 10^{10} \mathrm{~Pa}$ \\
\hline Machinability & $70 \%$ \\
\hline Shear Strength & $2.5 \times 10^{8} \mathrm{~Pa}$ \\
\hline \multicolumn{2}{|c|}{ Electrical Properties (Metric) } \\
\hline Resistivity (Electrical) & $4.90 \times 10^{-8} \Omega-\mathrm{m}$ \\
\hline \multicolumn{2}{|c|}{ Thermal Properties (Metric) } \\
\hline $\begin{array}{l}\text { Co-efficient of Thermal } \\
\text { Expansion (Linear) }\end{array}$ & $\begin{array}{c}2.4 \times 10^{-7} \mathrm{~m} / \mathrm{m}^{-}{ }^{\circ} \mathrm{C} @ \\
20.0-100^{\circ} \mathrm{C}\end{array}$ \\
\hline Conductivity (Thermal) & $164 \mathrm{~W} / \mathrm{m}-\mathrm{K}$ \\
\hline
\end{tabular}

Similarly, in case of 6013-T651 Al alloy, the extracted data acquired from experimentation while taking diverse load ratios is plotted using MATLAB software and that is demonstrated in Fig. 10 


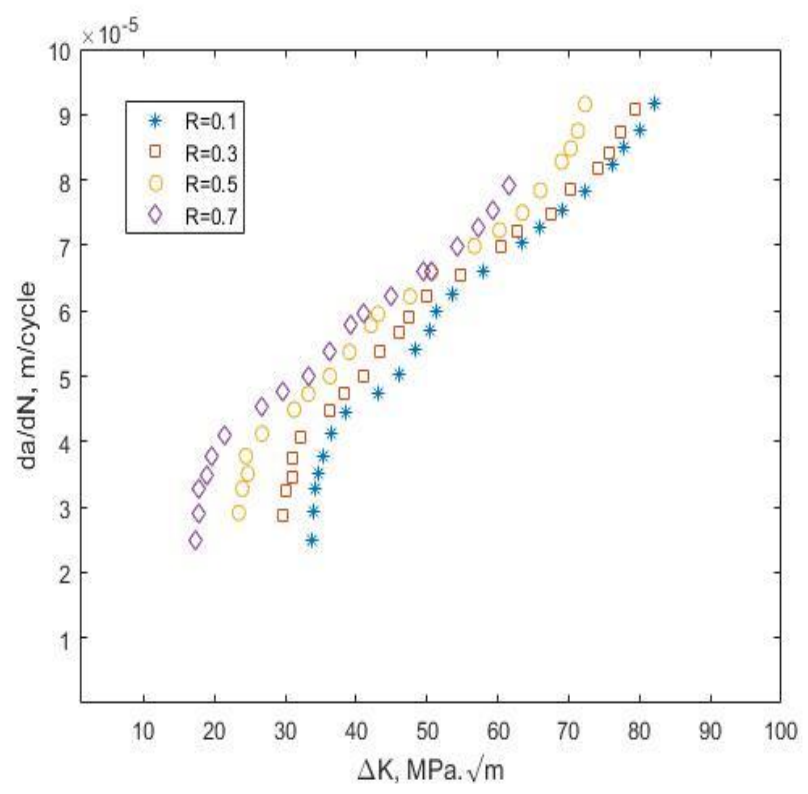

Fig. 10. Extracted data of Fatigue Crack Growth rate of 6013-T651 Al alloy through experimentation

A feasible methodology to predict Fatigue Crack Growth rate is introduced that uses three Machine Learning Algorithms among Optimized Neural Networks. In order to validate the practical effectiveness of the algorithms, the experimental data for different materials specifically used for commercial aircrafts is extracted and employed in the form of data sets. The three Optimized Neural Network based Machine Learning Algorithms are compared with each other and with previously used MLAs for crack growth rate prediction. For it, the 2-input and a 1-output model is designed. This is done by examining the vital forces for FCG rate by the application of forces of uniform amplitude.

All of the above algorithms are indorsed on three distinct $\mathrm{Al}$ alloys, used for manufacturing of aircraft bodies. The tentative information of the above mentioned alloys for four different cases of load ratios is acquired followed by plotting of these values using MATLAB 2016 as shown in Fig. 8. To accurately predict non-linearity in behavior in the process of FCG, this data is then randomly segregated and separated into training and testing sub sets. $70 \%$ section of sampling values are used for training while the remaining $30 \%$ is utilized for validating the efficiency of Machine Learning Algorithms based Optimized Neural Networks.

\subsection{Results:}

From Fig. 8, 9 \& 10 a non-linear behavior is depicted even in Paris region. In order to predict this abnormality from linearity more accurately, three MLA based Optimized Neural Networks are used. The anticipated outcomes alongside the tentative outcomes are plotted having a total number of values on horizontal axis while actual output is plotted on vertical axis for three above mentioned alloys using above mentioned machine learning techniques. The results using Genetic Algorithm based Optimized Neural Network for 2324-T39 Aluminum Alloy are shown in figure 11 . 


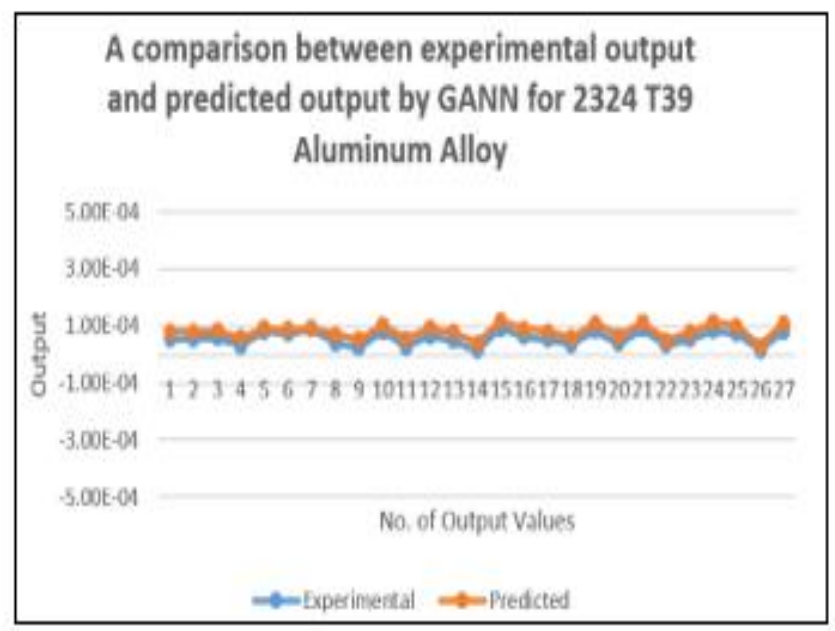

Fig. 11. Experimental and Predicted output graph of Genetic Algorithm optimized Neural Network for 2324-T39 Aluminum Alloy

Likewise, the results for 2324-T39 Aluminum Alloy are shown in figure 12 when Hill Climbing based Optimized Neural Network approach is used

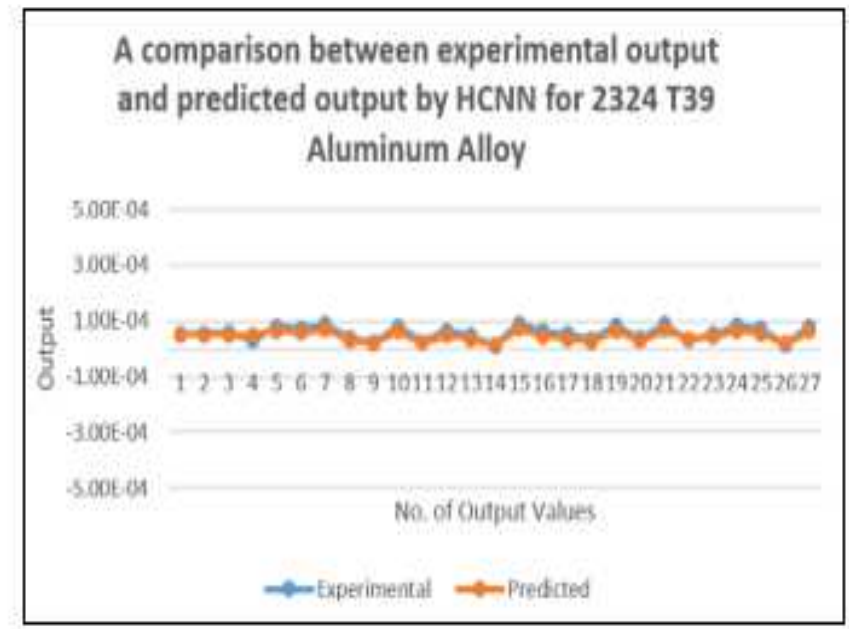

Fig. 12. Experimental and Predicted output graph of Hill Climbing Optimized Neural Network for 2324-T39 Aluminum Alloy

Similarly, the results using Simulated Annealing based Optimized Neural Network for 2324-T39 Aluminum Alloy are shown in figure 13. 


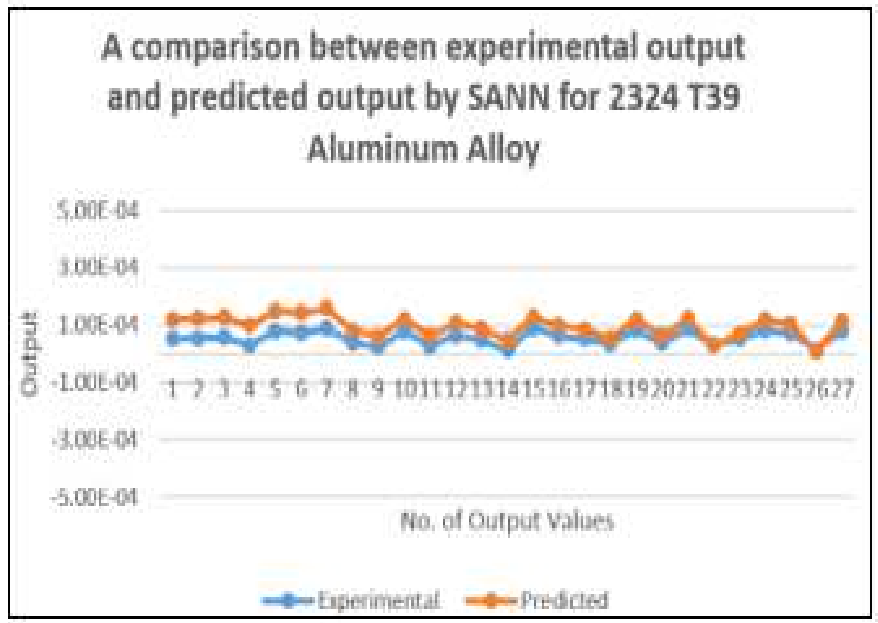

Fig. 13. Experimental and Predicted output graph of Simulated Annealing Optimized Neural Network for 2324-T39 Aluminum Alloy

The forecasted MSE's for the used techniques are demonstrated in Table 4.

Table 4. The parameters and results of FCG rate prediction using Optimized ANN algorithms on 2324-T39 Aluminum Alloy

\begin{tabular}{|c|c|c|c|c|c|}
\hline \multicolumn{6}{|c|}{ 2324-T39 Aluminum Alloy } \\
\hline Technique & $\begin{array}{l}\text { Number of } \\
\text { Input } \\
\text { Neurons }\end{array}$ & $\begin{array}{l}\text { Number of } \\
\text { Hidden } \\
\text { Neurons }\end{array}$ & $\begin{array}{c}\text { Number of } \\
\text { Output } \\
\text { Neurons }\end{array}$ & $\begin{array}{l}\text { Training } \\
\text { MSE }\end{array}$ & Predicted MSE \\
\hline $\begin{array}{c}\text { Genetic Algorithm optimized Neural } \\
\text { Network }\end{array}$ & 2 & 2 & 1 & $7.1930 \times 10^{-11}$ & $1.1687 \times 10^{-7}$ \\
\hline $\begin{array}{l}\text { Hill Climbing optimized Neural } \\
\text { Network }\end{array}$ & 2 & 2 & 1 & $3.2043 \times 10^{-11}$ & $3.1069 \times 10^{-8}$ \\
\hline $\begin{array}{c}\text { Simulated Annealing optimized } \\
\text { Neural Network }\end{array}$ & 2 & 2 & 1 & $5.8576 \times 10^{-10}$ & $2.1515 \times 10^{-7}$ \\
\hline
\end{tabular}

\section{A comparison between experimental output and predicted output by GANN for 7055-T7511 \\ Aluminum Alloy}

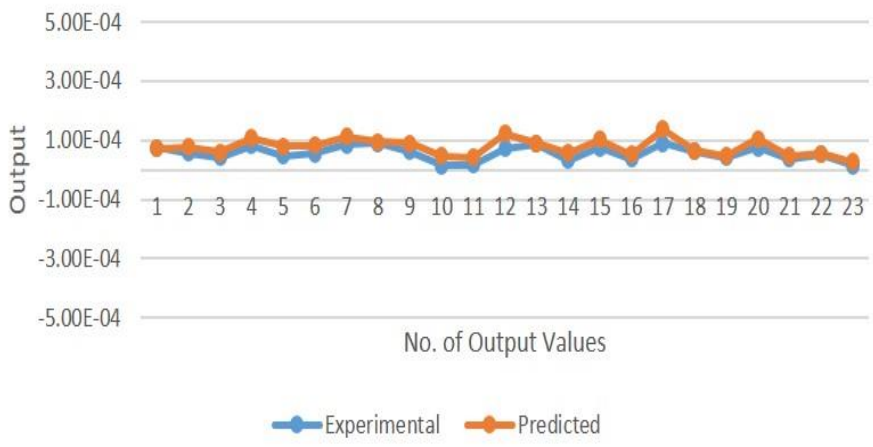

Fig. 14. Experimental and Predicted output graph of Genetic Algorithm optimized Neural Network for 7055-T7511 Aluminum Alloy 


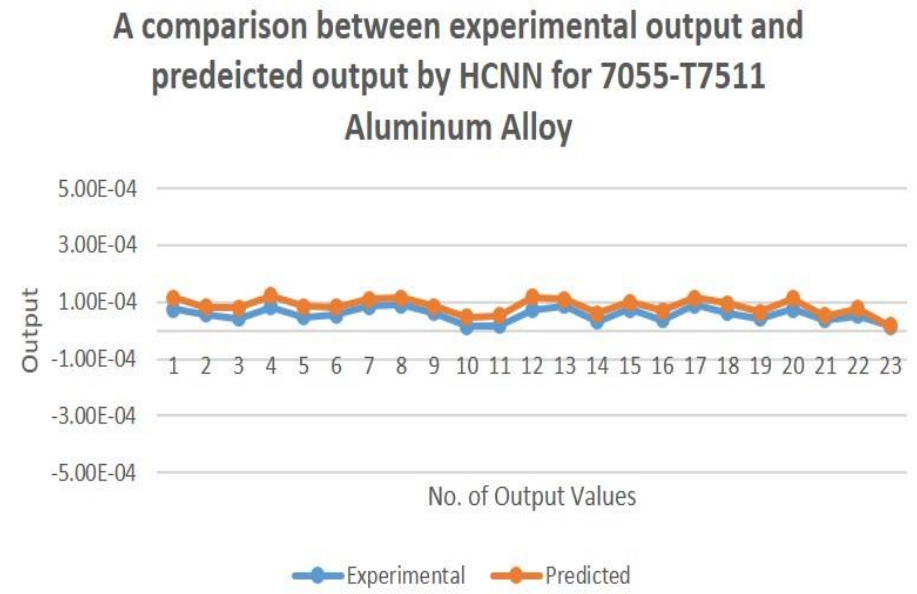

Fig. 15. Experimental and Predicted output graph Hill Climbing Optimized Neural Network for 7055-T7511 Aluminum Alloy

Likewise, the results for 7055-T7511 Aluminum Alloy are shown in figure 15 when Hill Climbing based Optimized Neural Network approach is used. Similarly, the results using Simulated Annealing based Optimized Neural Network for 7055-T7511 Aluminum Alloy are shown in figure 16.

\section{A comparison between experimental output and predicted output by SANN for 7055-T7511 \\ Aluminum Alloy}

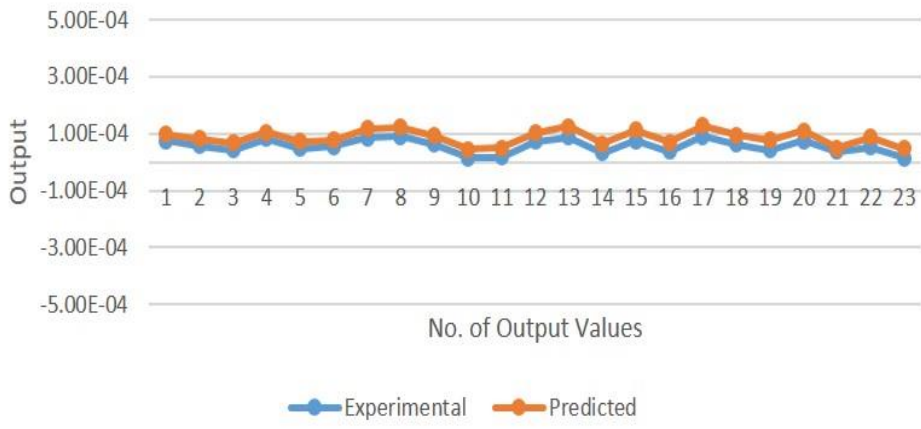

Fig. 16. Experimental and Predicted output graph of Simulated Annealing Optimized Neural Network for 7055-T7511 Aluminum Alloy

The forecasted MSE's for the used techniques are mentioned in Table 5.

Table 5. The parameters and results of FCG rate prediction using Optimized ANN algorithms on 7055-T7511 Aluminum Alloy

\begin{tabular}{|c|c|c|c|c|c|}
\hline \multicolumn{6}{|c|}{ 7055-T7511 Aluminum Alloy } \\
\hline Technique & $\begin{array}{c}\text { Number of } \\
\text { Input Neurons }\end{array}$ & $\begin{array}{c}\text { Number of } \\
\text { Hidden Neurons }\end{array}$ & $\begin{array}{c}\text { Number of } \\
\text { Output Neurons }\end{array}$ & Training MSE & $\begin{array}{l}\text { Predicted } \\
\text { MSE }\end{array}$ \\
\hline $\begin{array}{l}\text { Genetic Algorithm optimized Neural } \\
\text { Network }\end{array}$ & 2 & 2 & 1 & $1.3073 \times 10^{-10}$ & $6.6669 \times 10^{-8}$ \\
\hline $\begin{array}{l}\text { Hill Climbing optimized Neural } \\
\text { Network }\end{array}$ & 2 & 2 & 1 & $8.3832 \times 10^{-11}$ & $1.4284 \times 10^{-9}$ \\
\hline $\begin{array}{c}\text { Simulated Annealing optimized Neural } \\
\text { Network }\end{array}$ & 2 & 2 & 1 & $4.2147 \times 10^{-10}$ & $1.4512 \times 10^{-8}$ \\
\hline
\end{tabular}


The results using Genetic Algorithm based Optimized Neural Network for 6013-T651 Aluminum Alloy are depicted in Fig. 17.

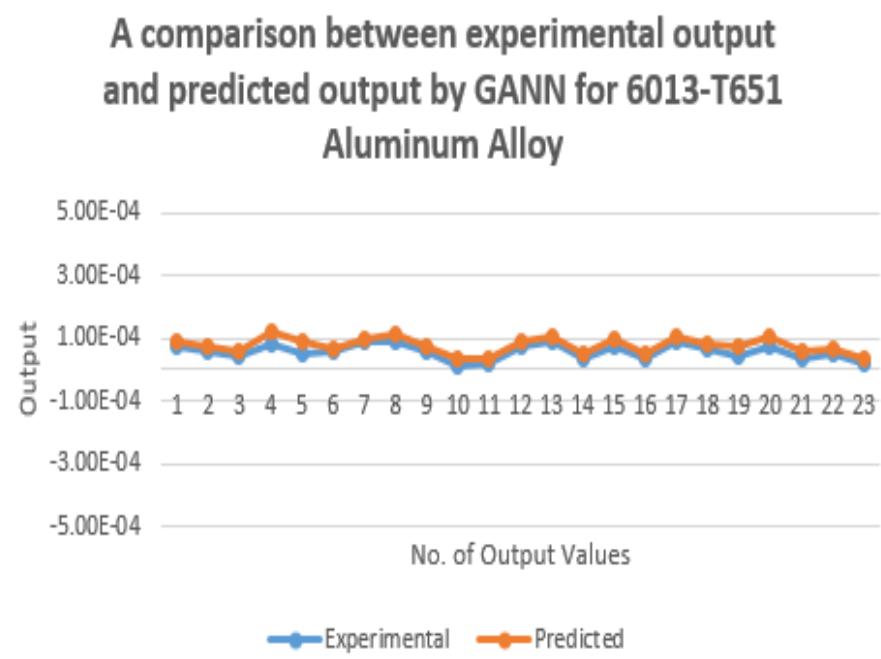

Fig. 17. Experimental and Predicted output graph of Genetic Algorithm optimized Neural Network for 6013-T651 Aluminum Alloy

Likewise, the results for 6013-T651 Aluminum Alloy are shown in Fig. 18 when Hill Climbing based Optimized Neural Network approach is used.

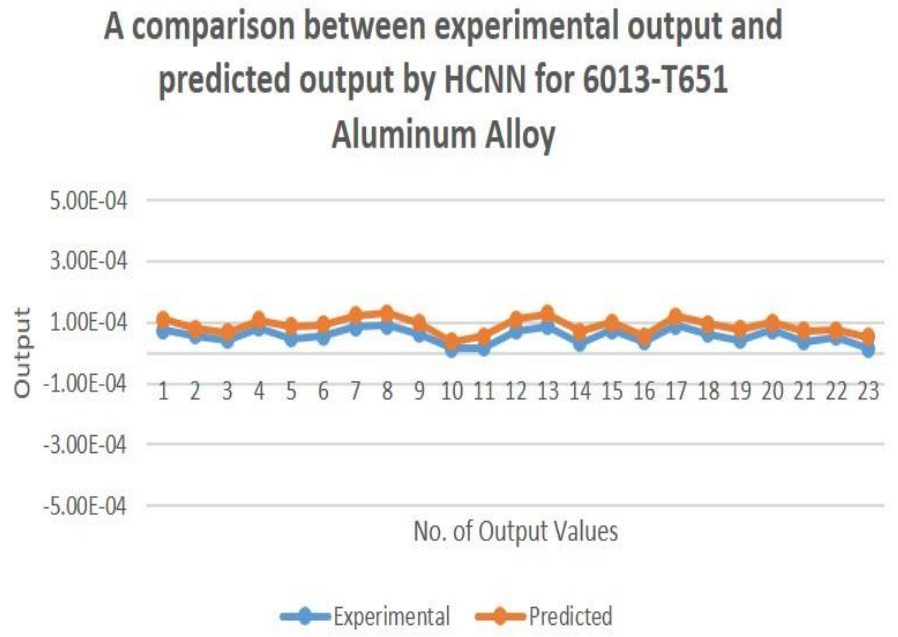

Fig. 18. Experimental and Predicted output graph of Hill Climbing Optimized Neural Network for 6013-T651 Aluminum Alloy Similarly, the results using Simulated Annealing based Optimized Neural Network for 6013-T651 Aluminum Alloy are depicted in Fig. 19. 


\section{A comparison between experimental output and predeicted output by SANN for 6013-T651 Aluminum Alloy}

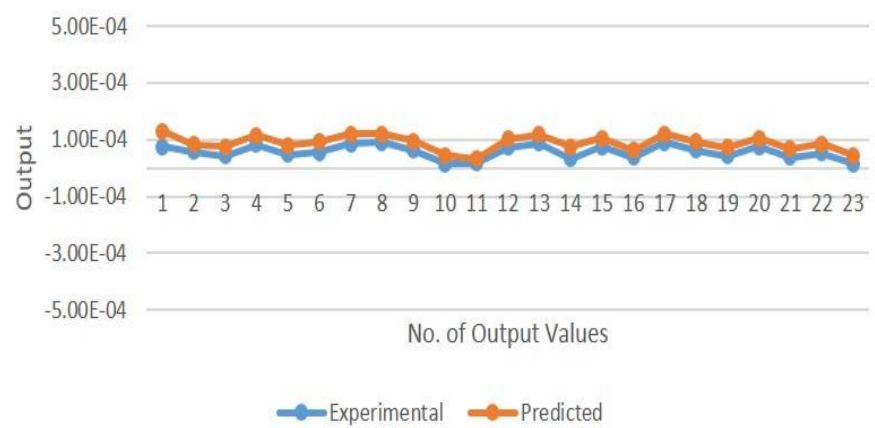

Fig. 19. Experimental and Predicted output graph of Simulated Annealing Optimized Neural Network for 6013-T651 Aluminum Alloy

The forecasted MSE's for the used techniques are mentioned in Table 6.

Table 6. The parameters and results of FCG rate prediction using Optimized ANN algorithms on 7055-T7511 Aluminum Alloy

\begin{tabular}{|c|c|c|c|c|c|}
\hline \multicolumn{5}{|c|}{ 6013-T651 Aluminum Alloy } \\
\hline Technique & $\begin{array}{c}\text { Number of } \\
\text { Input Neurons }\end{array}$ & $\begin{array}{c}\text { Number of } \\
\text { Hidden Neurons }\end{array}$ & $\begin{array}{c}\text { Number of } \\
\text { Output Neurons }\end{array}$ & $\begin{array}{c}\text { Training } \\
\text { MSE }\end{array}$ & $\begin{array}{c}\text { Predicted } \\
\text { MSE }\end{array}$ \\
\hline $\begin{array}{c}\text { Genetic Algorithm Optimized Neural } \\
\text { Network }\end{array}$ & 2 & 2 & 1 & $6.4575 \times 10^{-11}$ & $3.6246 \times 10^{-8}$ \\
\hline $\begin{array}{c}\text { Hill Climbing Optimized Neural } \\
\text { Network }\end{array}$ & 2 & 2 & 1 & $5.5249 \times 10^{-12}$ & $6.2171 \times 10^{-9}$ \\
\hline $\begin{array}{c}\text { Simulated Annealing Optimized } \\
\text { Neural Network }\end{array}$ & 2 & 2 & 1 & $2.8805 \times 10^{-10}$ & $1.0559 \times 10^{-9}$ \\
\hline
\end{tabular}

\section{Conclusion}

Material failure is an important and serious problem. Many accidents in the past are the result of failure of structures occurred due to excessive fatigue which has claimed lives of many people besides economic loss. Non-linearity in FCG curve is addressed using various analytical, hybrid and machine learning techniques in order to predict FCG rate perfectly. In an attempt to do so, in this research MLA based FCG calculation method is proposed. The regression based ANN model is utilized in order to foretell FCG rate with minimum error. A 2-1 network is established for this purpose. Stress Intensity Factor range and R-ratio effects for the above mentioned materials that are in application for aircraft structures are taken into account as inputs of established optimized networks to predict their crack growth rate. A 2-1 network is undergone through training process contrary to definite stopping settings. Upon comparing results for three different commercially used alloys, it is observed that Hill Climbing based Optimized Neural Network shows better results when compared with other algorithms used in the proposed methodology for 2324-T39 aluminum alloy. For 7055-T7511 aluminum alloy as well, Hill Climbing based Optimized Neural Network has minimum predicted MSE as compared to Genetic Algorithm based Optimized Neural Network and Simulated Annealing based Optimized Neural Network. In contrast, Simulated Annealing based Optimized Neural Network shows better results for 6013-T651 aluminum alloy amongst other algorithms. Taking all the three algorithms used in the proposed technique into account for three alloys, it can be inferred upon looking at the results that Simulated Annealing based Optimized Neural Network has given better results for 6013T651 aluminum alloy when compared with others. The predicted MSE for SANN with 6013-T651 alloy is $1.0559 \times 10^{-9}$. The projected data displays a decent correspondence with experimental data and Optimized Neural Networks address the non-linearities of FCG rate suitably. There is another observation upon viewing predicted and 
experimental curves that the extrapolative curves over-fits the experimental curves at various stages. This behavior of over-fitting can be evaded through cross confirmation of the data and calculating correctness over and over again.

\section{Acknowledgement}

The experimentation work is supported by Fracture Technology Associates that is situated in Bethlehem, PA, USA.

\section{Nomenclature}

$\Delta K=$ Stress Intensity Factor Range

$R=$ Stress Ratio

$K_{c}=$ Fracture Toughness

\section{References}

[1] Paris, P. C., \& Erdogan, F. "A critical analysis of crack propagation laws." ASME ((1963, December)).

[2] Forman, R. G., Kearney, V. E., \& Engle, R. M. "Numerical analysis of crack propagation in cyclic-loaded structures." Journal of basic Engineering (1967): 89(3), 459-463.

[3] Priddle, E. K. "High cycle fatigue crack propagation under random and constant amplitude loadings." International Journal of Pressure Vessels and Piping (1976): 4(2), 89-117.

[4] Elber, W. "The significance of fatigue crack closure. ." In Damage tolerance in aircraft structures. ASTM International. (1971).

[5] Kujawski, D. "A new ( $\Delta \mathrm{K}+\mathrm{K}$ max) 0.5 driving force parameter for crack growth in aluminum alloys. ." International Journal of Fatigue (2001): 23(8), 733-740.

[6] Donald, J. K., Bray, G. H., \& Bush, R. W. "Introducing the K \{sub max \} sensitivity concept for correlating fatigue crack growth data (No. CONF-970980--). ." The Minerals, Metals and Materials Society, Warrendale, PA (United States). (1997). [7] Sadananda, K., \& Vasudevan, A. K. "Analysis of fatigue crack closure and thresholds. ." Fracture Mechanics: 25th Volume. ASTM International. (1995).

[8] Dinda, S., \& Kujawski, D. "Correlation and prediction of fatigue crack growth for different R-ratios using $\mathrm{K}$ max and $\Delta \mathrm{K}+$ parameters." Engineering Fracture Mechanics (2004): 71(12), 1779-1790.

[9] Bui, T. Q., Tran, A. V., \& Shah, A. A. "Improved knowledge-based neural network (KBNN) model for predicting springback angles in metal sheet bending." International Journal of Modeling, Simulation, and Scientific Computing (2014): 5(02), 1350026.

[10] Bhattacharya, S., Singh, I. V., Mishra, B. K., \& Bui, T. Q. "Fatigue crack growth simulations of interfacial cracks in bilayered FGMs using XFEM." Computational Mechanics (2013): 52(4), 799-814.

[11] Hu, X., Bui, T. Q., Wang, J., Yao, W., Ton, L. H. T., Singh, I. V., \& Tanaka, S. "). A new cohesive crack tip symplectic analytical singular element involving plastic zone length for fatigue crack growth prediction under variable amplitude cyclic loading." European Journal of Mechanics-A/Solids (2017): 65, 79-90.

[12] Mohanty, J. R., Verma, B. B., Parhi, D. R. K., \& Ray, P. K. "Application of artificial neural network for predicting fatigue crack propagation life of aluminum alloys." (2009).

[13] Rodríguez, J. A., Hamzaoui, Y. E., Hernández, J. A., García, J. C., Flores, J. E., \& Tejeda, A. L. "The use of artificial neural network (ANN) for modeling the useful life of the failure assessment in blades of steam turbines." Engineering Failure Analysis (2013): 35, 562-575.

[14] Rafiq, M. Y., Bugmann, G., \& Easterbrook, D. J. "Neural network design for engineering applications." Computers \& Structures (2001): 79(17), 1541-1552.

[15] Venkatesh, V., \& Rack, H. J. "A neural network approach to elevated temperature creep-fatigue life prediction." International Journal of Fatigue (1999): 21(3), 225-234.

[16] Artymiak, P., Bukowski, L., Feliks, J., Narberhaus, S., \& Zenner, H. "Determination of S-N curves with the application of artificial neural networks. ." Fatigue \& Fracture of Engineering Materials \& Structures (1999): 22(8), 723-728.

[17] Kang, J. Y., \& Song, J. H. "Neural network applications in determining the fatigue crack opening load." International journal of fatigue (1998): 20(1), 57-69.

[18] Haque, M. E., \& Sudhakar, K. V. "Prediction of corrosion-fatigue behavior of DP steel through artificial neural network." International Journal of Fatigue (2001): 23(1), 1-4.

[19] Cheng, Y., W.L. Huang and C.Y. Zhou. "Artificial neural network technology for the data processing of on-line corrosion fatigue crack growth monitoring." Int. J. Pres. Ves. Pip. (1999): 76, 113-116.

[20] Zio, E., \& Di Maio, F. "Fatigue crack growth estimation by relevance vector machine. ." Expert Systems with Applications (2012): 39(12), 10681-10692.

[21] Mohanty, J. R., Mahanta, T. K., Mohanty, A., \& Thatoi, D. N. "Prediction of constant amplitude fatigue crack growth life of 2024 T3 Al alloy with R-ratio effect by GP." Applied Soft Computing (2015): 26, 428-434. 
[22] Zhang, W., Bao, Z., Jiang, S., \& He, J. "An Artificial Neural Network-Based Algorithm for Evaluation of Fatigue Crack Propagation Considering Nonlinear Damage Accumulation." Materials (2016): 9(6), 483.

[23] Wang, H., Zhang, W., Sun, F., \& Zhang, W. "A Comparison Study of Machine Learning Based Algorithms for Fatigue Crack Growth Calculation." Materials (2017): 10(5), 543.

[24] Paris, P. C., Tada, H., \& Donald, J. K. "Service load fatigue damage-a historical perspective." International Journal of fatigue (1999): vol. 21, pp. S35-S46.

[25] Donald, K., \& Paris, P. C. "An evaluation of $\Delta$ Keff estimation procedures on 6061-T6 and 2024-T3 aluminum alloys."

International Journal of fatigue (1999): vol. 21, pp. S47-S57.

\section{Declaration of interests}

$\bigotimes$ The authors declare that they have no known competing financial interests or personal relationships that could have appeared to influence the work reported in this paper.

$\bigotimes$ The authors declare the following financial interests/personal relationships which may be considered as potential competing interests:

Dr. Khurram Kamal (Corresponding Author)

Engr. Hassan Bin Younis

Engr. Muhammad Fahad Sheikh

Dr. Amir Hamza

\section{Funding Notes}

This research was not sponsored by any funding agency or organization.

\section{Availability of data and materials}

Data will made available on request.

\section{Authors' contributions}

Conceptualization: Dr. Khurram Kamal and Dr. Amir Hamza; Methodology: Hassan Bin Younis and Muhammad Fahad Sheikh; Format analysis: Hassan Bin Younis; Investigation: Dr. Khurram Kamal, Muhammad Fahad Sheikh; writing — original draft preparation: Hassan Bin Younis; writing—review: Muhammad Fahad Sheikh 

Figures

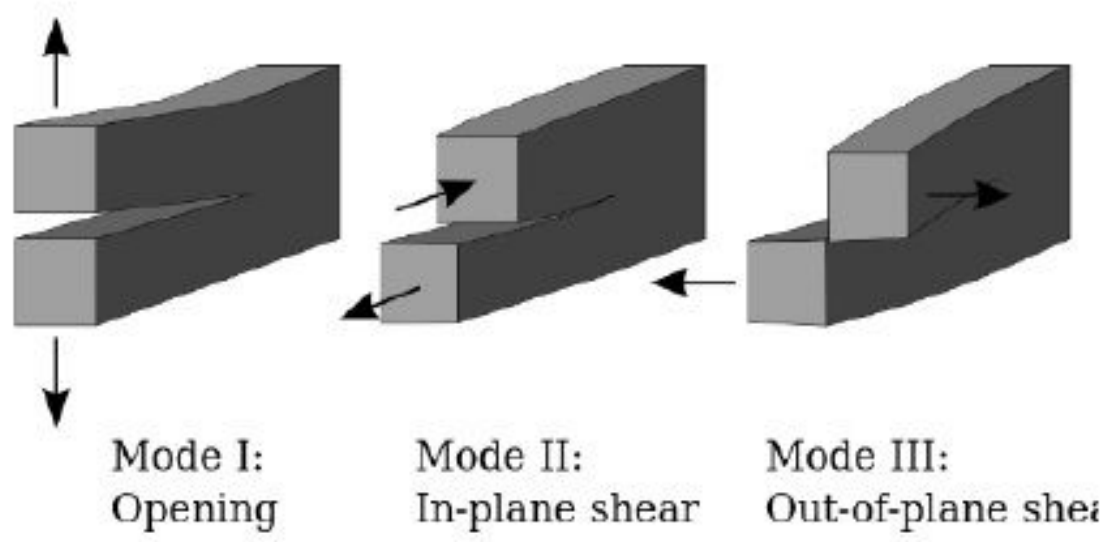

Figure 1

Modes of Failure during Engagement of Crack Propagation

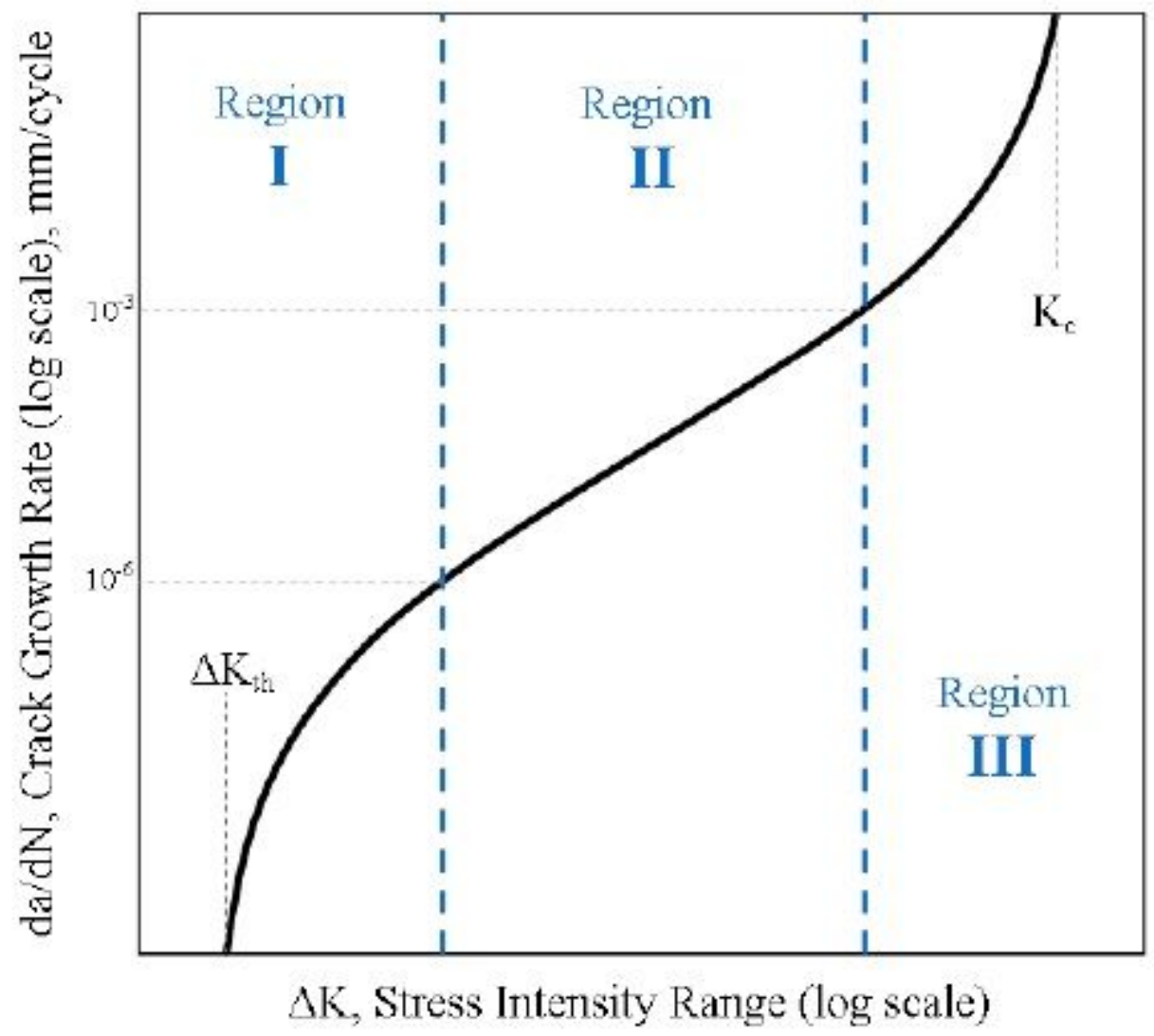

Figure 2

Generalized Fatigue Crack Growth Rate Curve 


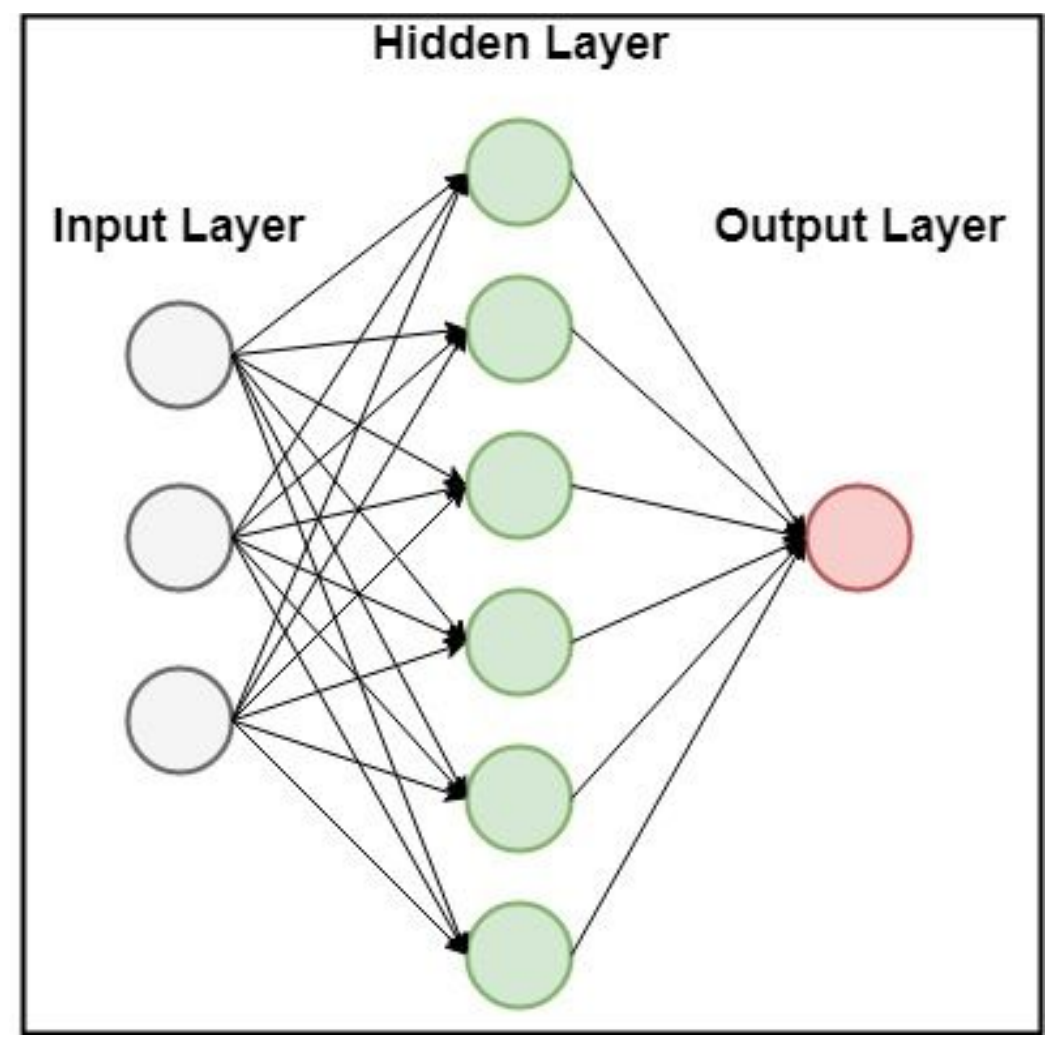

Figure 3

A Structure of a Feed Forward Neural Network 


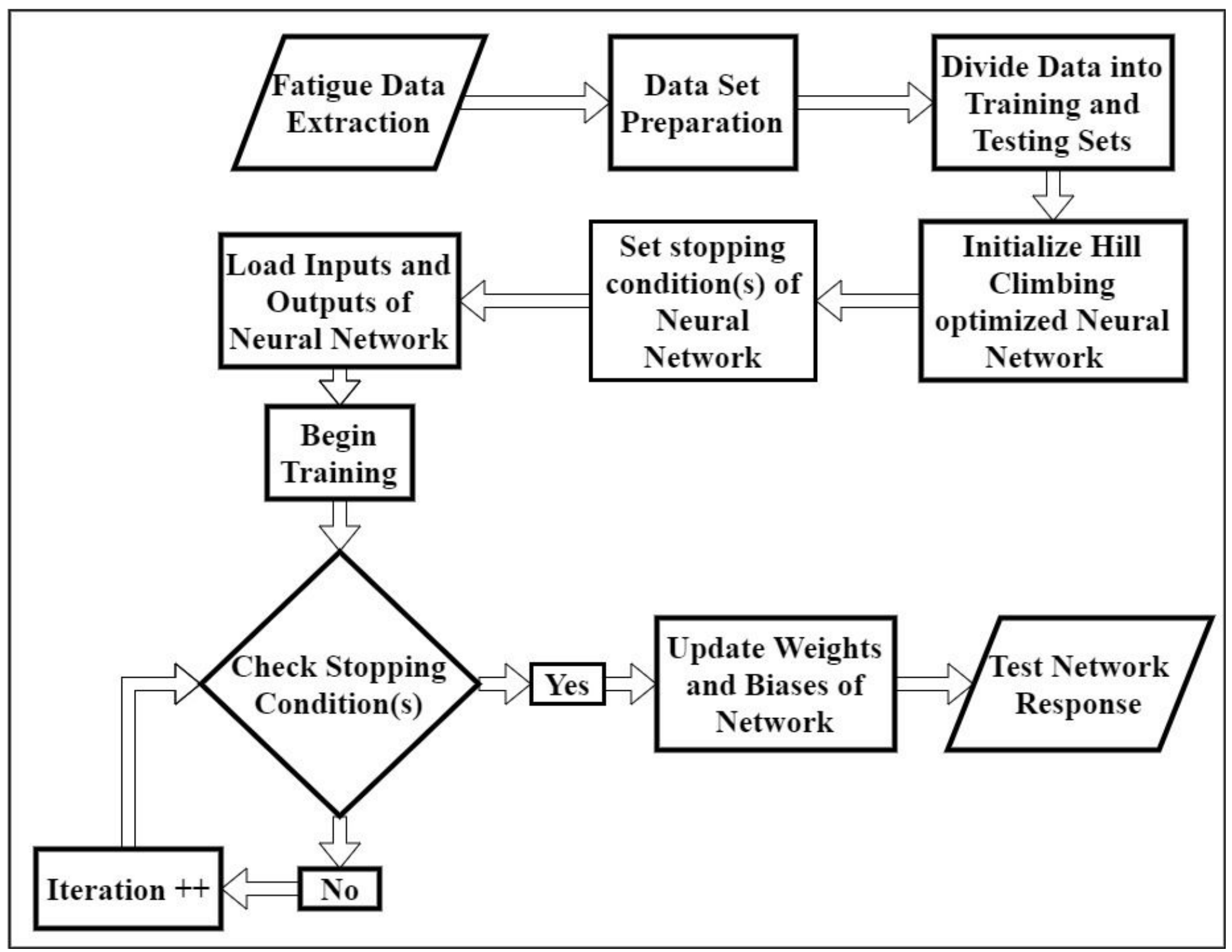

Figure 4

A Flowchart of Proposed Technique using Hill Climbing Based Optimized Neural Network 


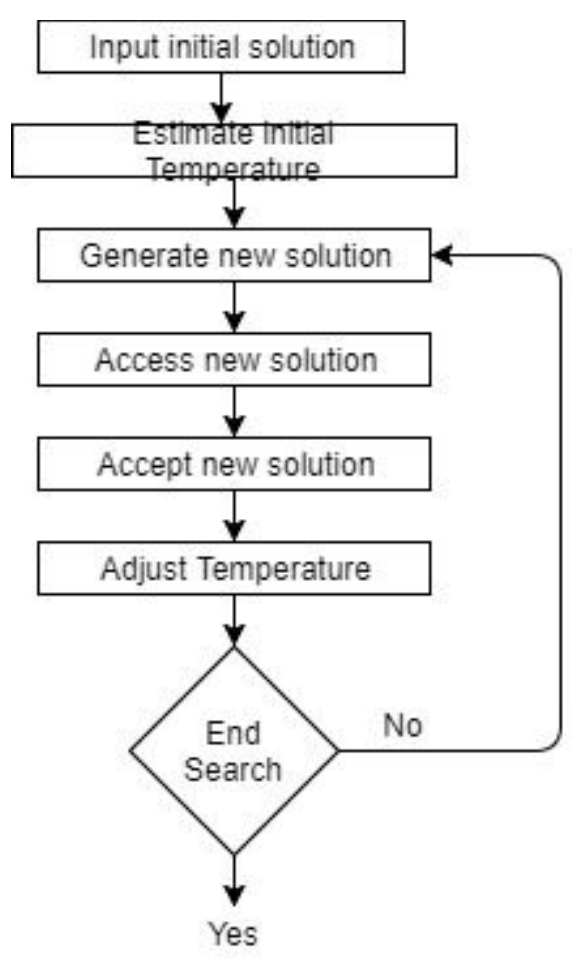

Figure 5

A Flowchart of Generalized Simulated Annealing Based Optimized Neural Network 


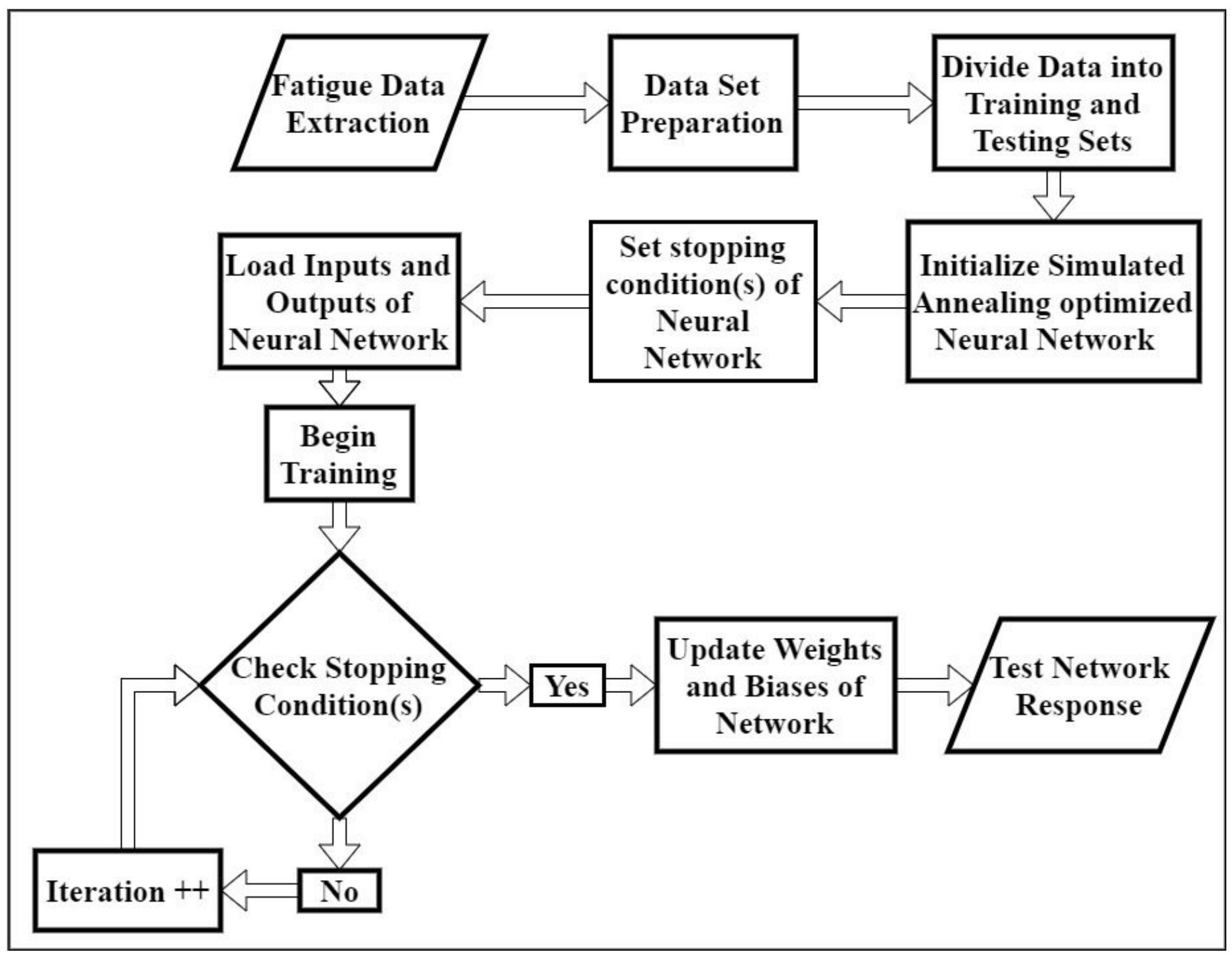

Figure 6

A Flowchart of Proposed Technique using Simulated Annealing Based Optimized Neural Network 


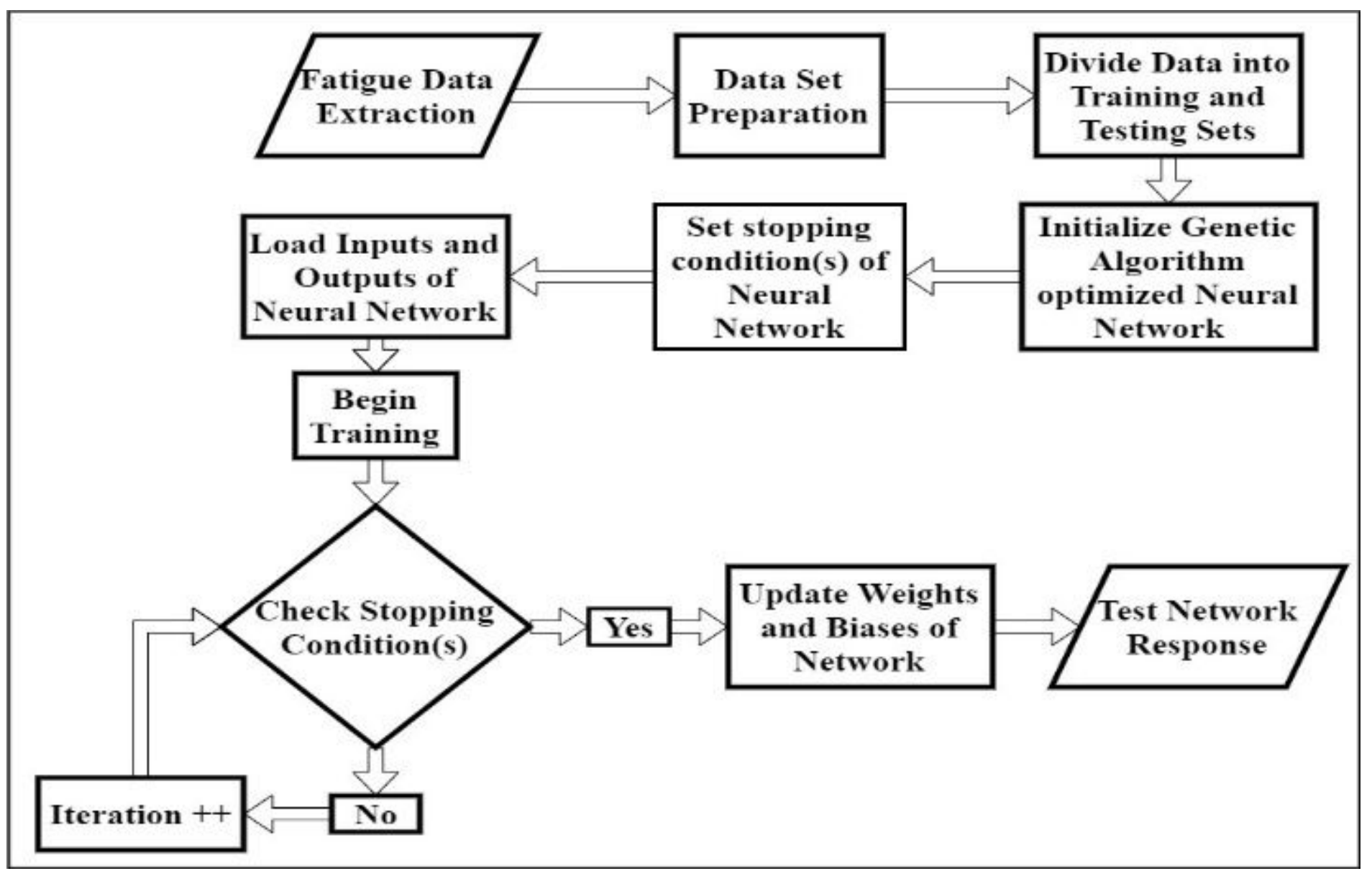

Figure 7

A Flowchart of Proposed Technique using Genetic Algorithm Based Optimized Neural Network 


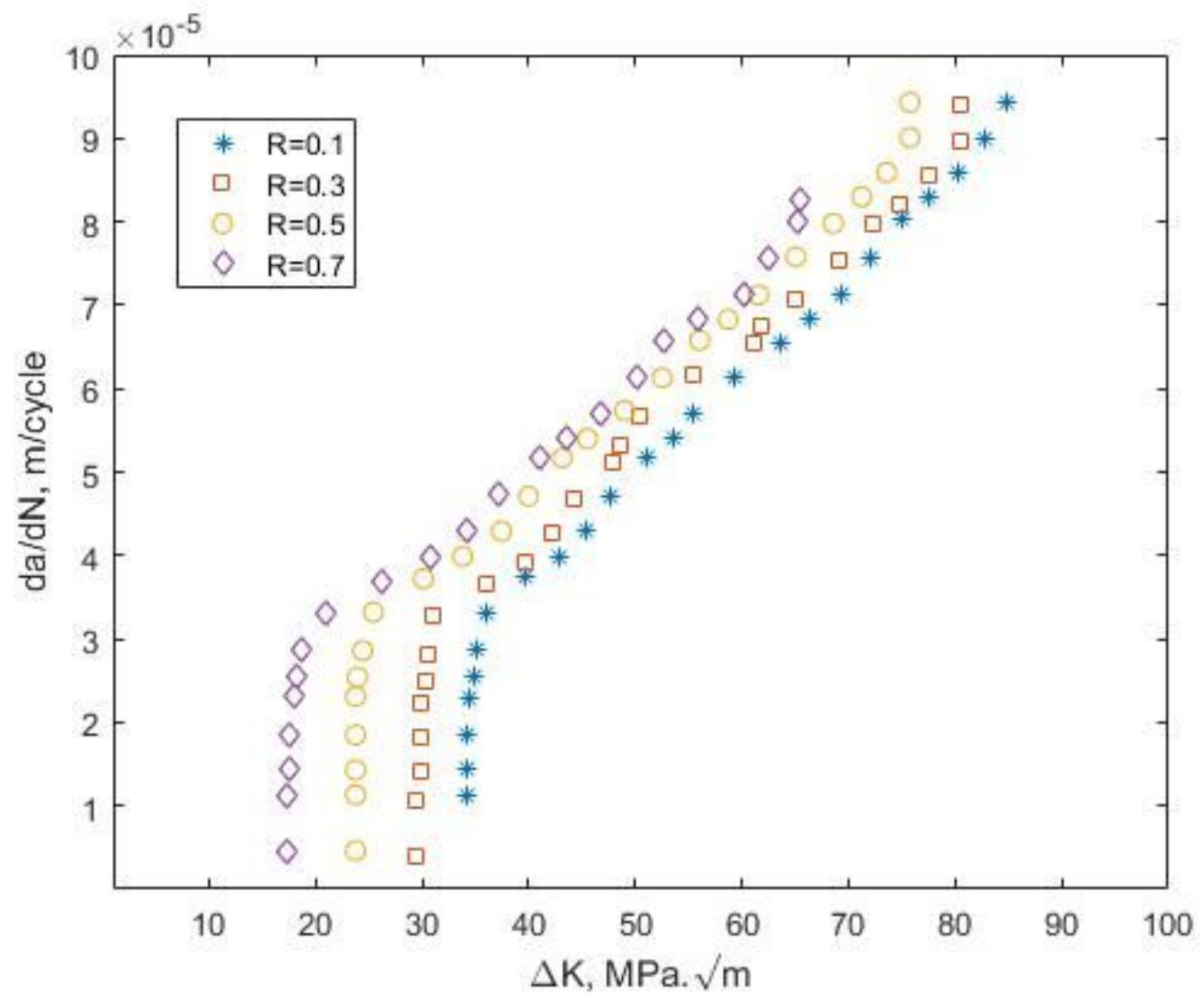

Figure 8

Extracted data of Fatigue Crack Growth rate of 2324-T39 Al alloy through experimentation

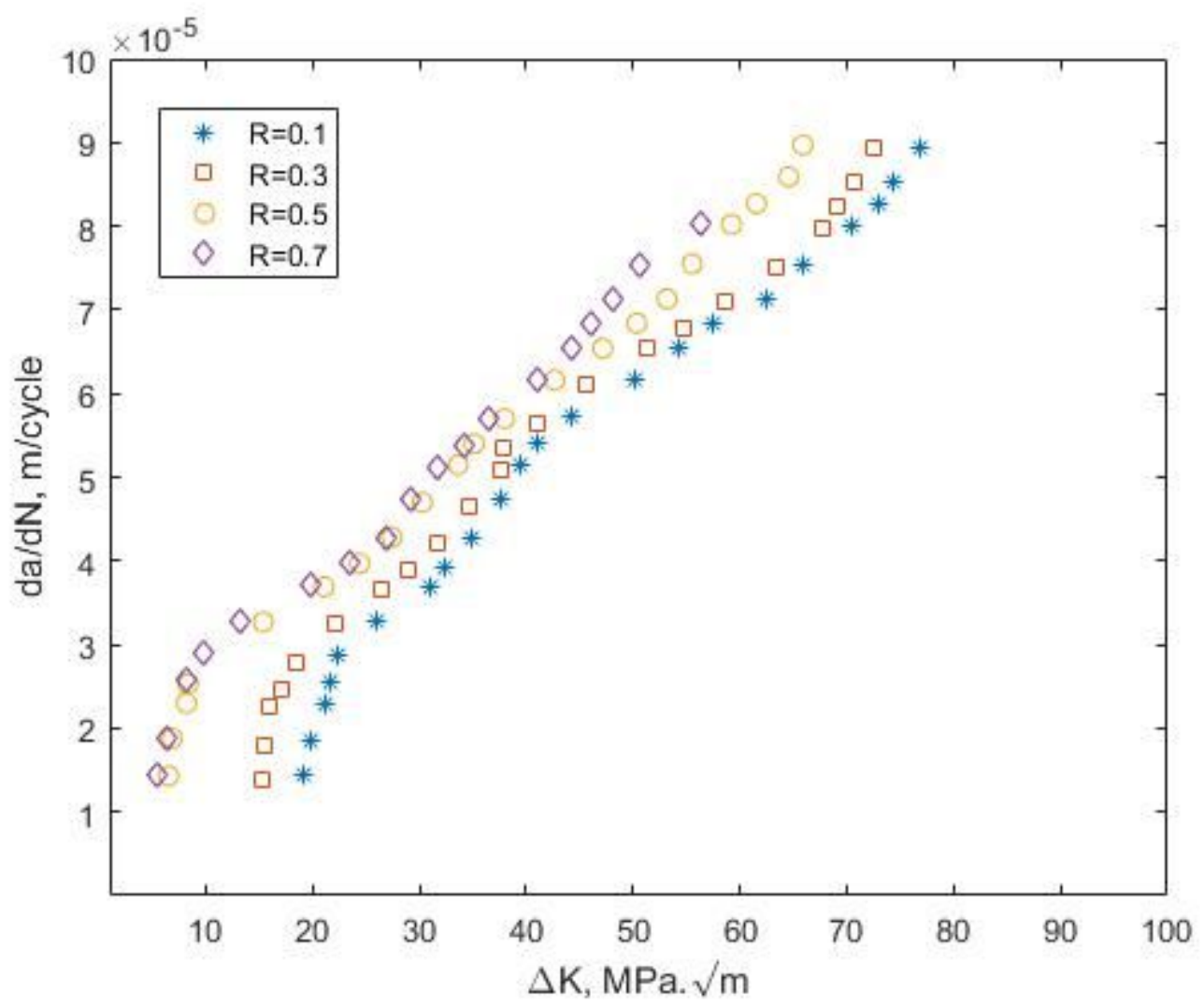


Figure 9

Extracted data of Fatigue Crack Growth rate of 7055-T7511 Al alloy through experimentation

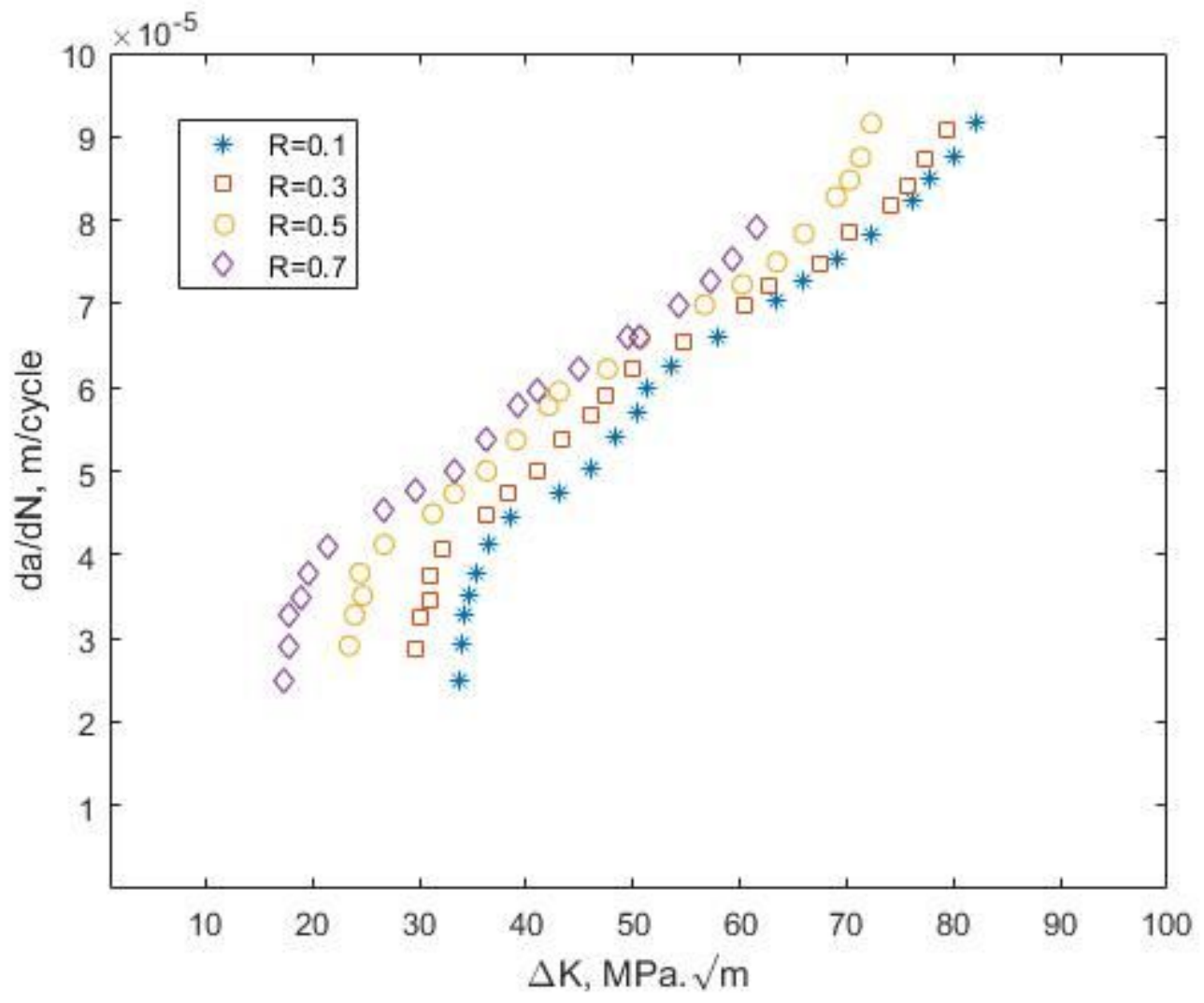

Figure 10

Extracted data of Fatigue Crack Growth rate of 6013-T651 Al alloy through experimentation

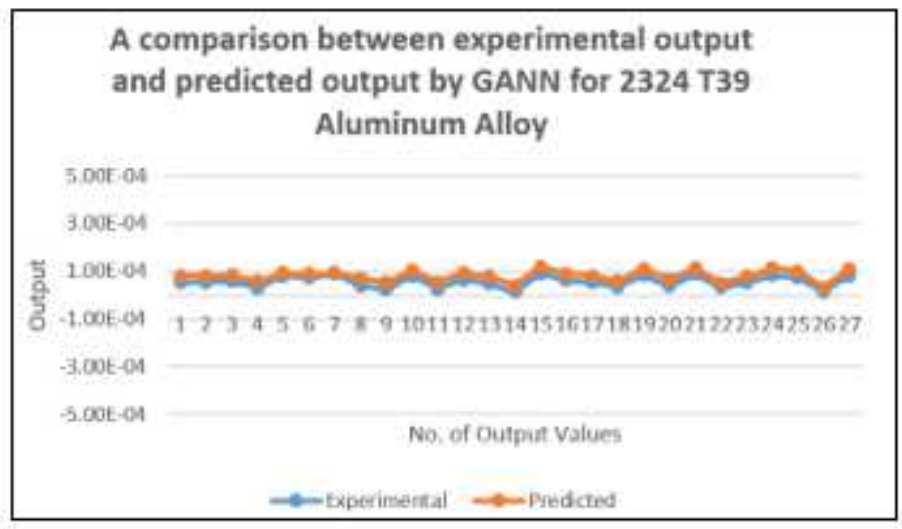

Figure 11

Experimental and Predicted output graph of Genetic Algorithm optimized Neural Network for 2324-T39 Aluminum Alloy 


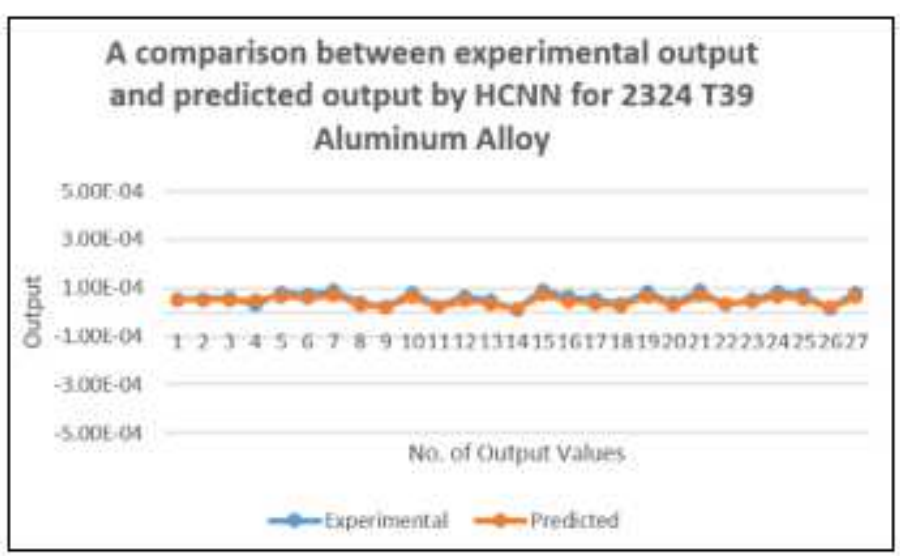

\section{Figure 12}

Experimental and Predicted output graph of Hill Climbing Optimized Neural Network for 2324-T39 Aluminum Alloy

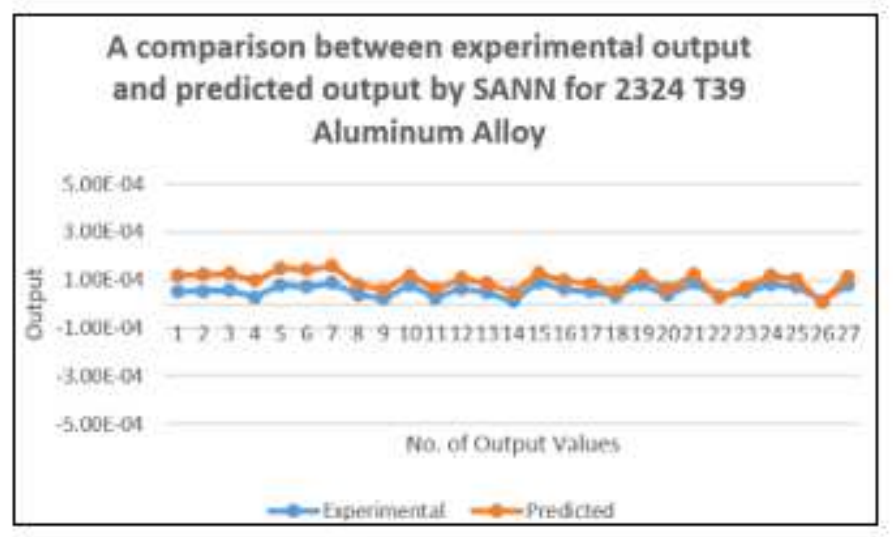

Figure 13

Experimental and Predicted output graph of Simulated Annealing Optimized Neural Network for 2324-T39 Aluminum Alloy 


\section{A comparison between experimental output and predicted output by GANN for 7055-T7511 \\ Aluminum Alloy}

$$
\begin{array}{r}
5.00 \mathrm{E}-04 \\
3.00 \mathrm{E}-04 \\
\stackrel{5}{\mathrm{~J}} 1.00 \mathrm{E}-04 \\
\stackrel{5}{5}-1.00 \mathrm{E}-04 \\
-3.00 \mathrm{E}-04 \\
-5.00 \mathrm{E}-04
\end{array}
$$
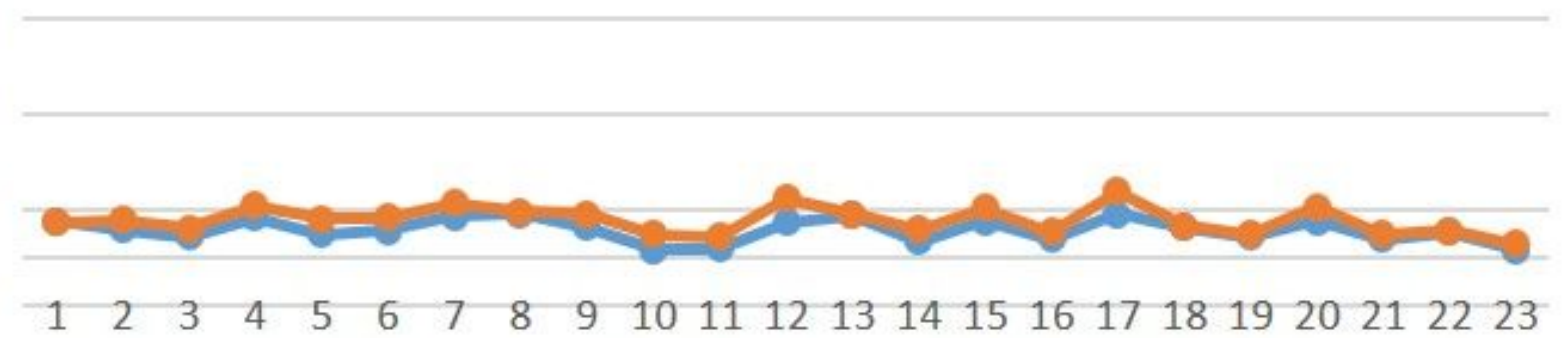

No. of Output Values

$\longrightarrow$ Experimental $\longrightarrow$ Predicted

\section{Figure 14}

Experimental and Predicted output graph of Genetic Algorithm optimized Neural Network for 7055-T7511 Aluminum Alloy

\section{A comparison between experimental output and predeicted output by HCNN for 7055-T7511 Aluminum Alloy}

\subsection{E-04 \\ $3.00 \mathrm{E}-04$

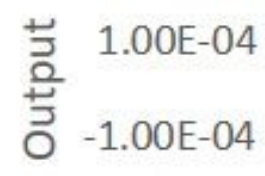 $-3.00 \mathrm{E}-04$ $-5.00 \mathrm{E}-04$} No. of Output Values

$\longrightarrow$ Experimental $\longrightarrow$ Predicted 
Figure 15

Experimental and Predicted output graph Hill Climbing Optimized Neural Network for 7055-T7511 Aluminum Alloy

\section{A comparison between experimental output and predicted output by SANN for 7055-T7511 \\ Aluminum Alloy}

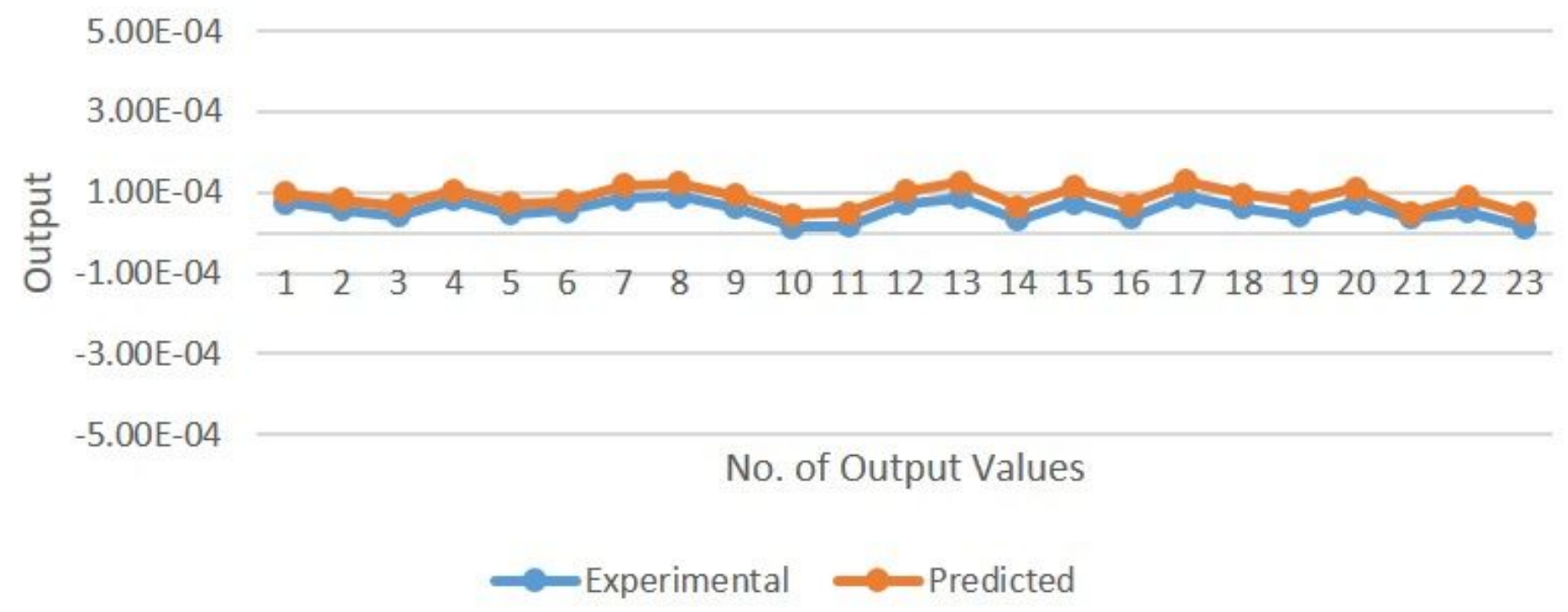

\section{Figure 16}

Experimental and Predicted output graph of Simulated Annealing Optimized Neural Network for 7055T7511 Aluminum Alloy

A comparison between experimental output and predicted output by GANN for 6013-T651

Aluminum Alloy

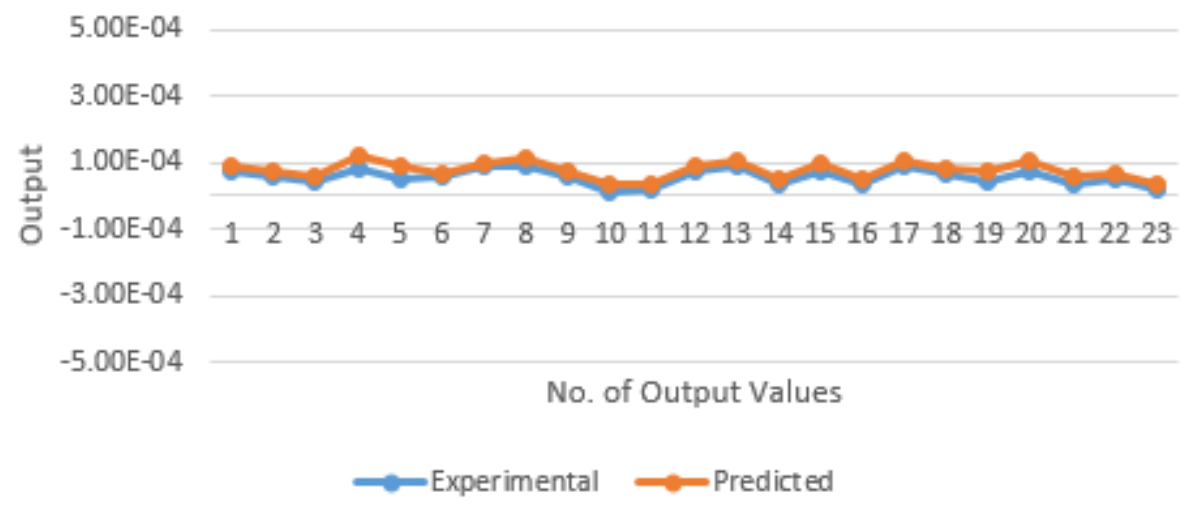

Figure 17 
Experimental and Predicted output graph of Genetic Algorithm optimized Neural Network for 6013-T651 Aluminum Alloy

\section{A comparison between experimental output and predicted output by HCNN for 6013-T651 Aluminum Alloy}

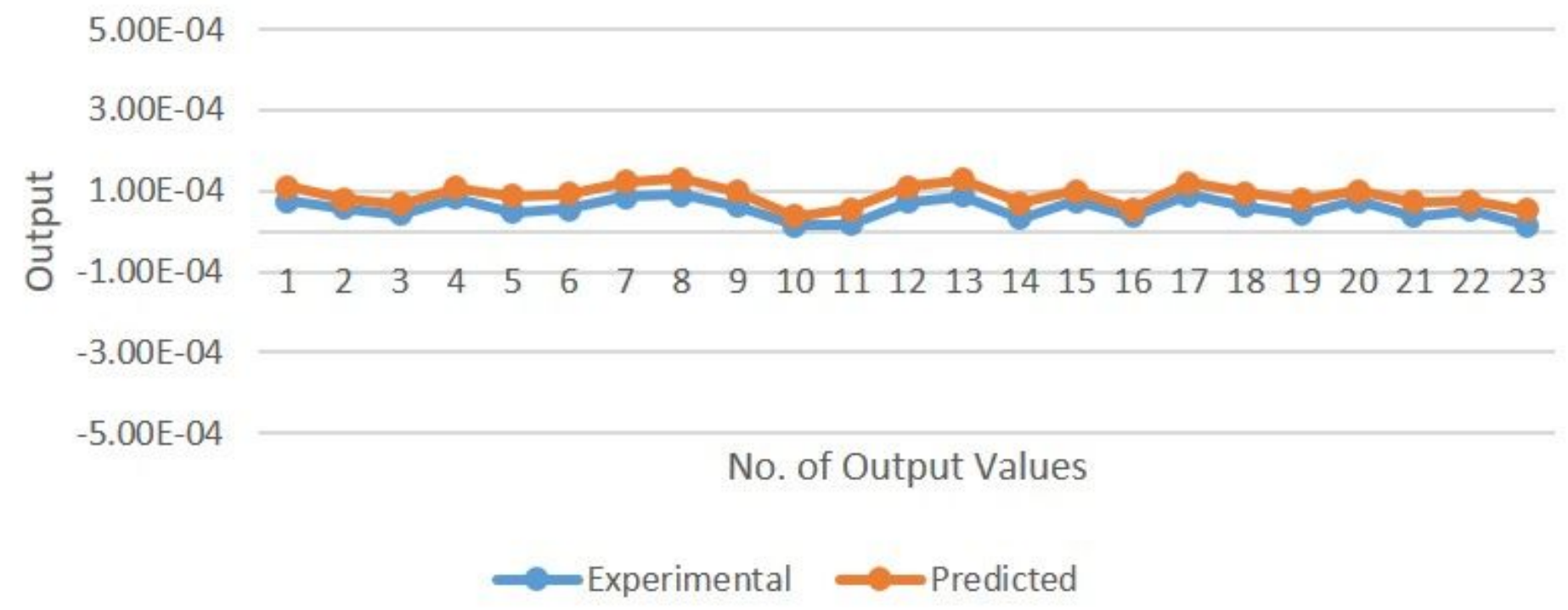

Figure 18

Experimental and Predicted output graph of Hill Climbing Optimized Neural Network for 6013-T651 Aluminum Alloy 


\section{A comparison between experimental output and predeicted output by SANN for 6013-T651 Aluminum Alloy}

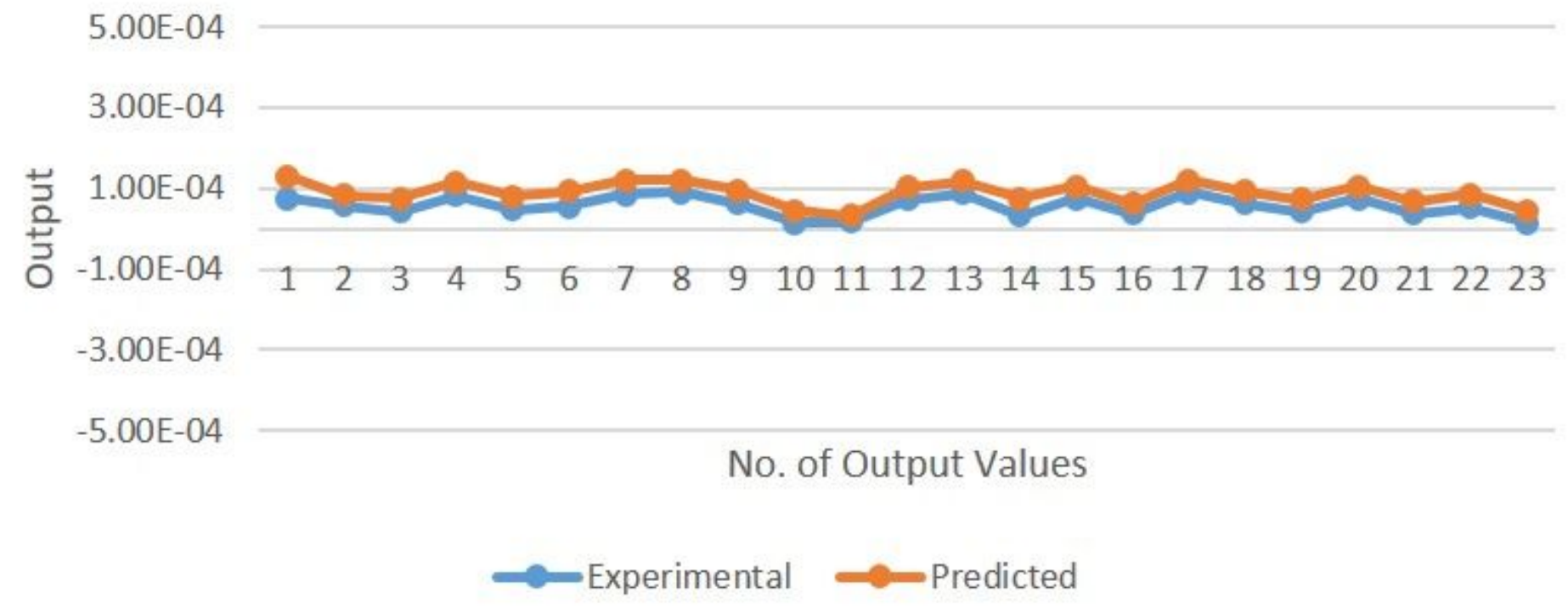

Figure 19

Experimental and Predicted output graph of Simulated Annealing Optimized Neural Network for 6013T651 Aluminum Alloy 